\title{
Augmented $\beta 2$-adrenergic signaling dampens the neuroinflammatory response following ischemic stroke and increases stroke size
}

Kendra J. Lechtenberg ${ }^{1}$, Scott T. Meyer ${ }^{1}$, Janelle B. Doyle ${ }^{1}$, Todd C. Peterson ${ }^{1}$ and Marion S. Buckwalter ${ }^{1,2^{*}}$ (D)

\begin{abstract}
Background: Ischemic stroke provokes a neuroinflammatory response and simultaneously promotes release of epinephrine and norepinephrine by the sympathetic nervous system. This increased sympathetic outflow can act on $\beta 2$-adrenergic receptors expressed by immune cells such as brain-resident microglia and monocyte-derived macrophages (MDMs), but the effect on post-stroke neuroinflammation is unknown. Thus, we investigated how changes in $\beta 2$-adrenergic signaling after stroke onset influence the microglia/MDM stroke response, and the specific importance of microglia/MDM $\beta 2$-adrenergic receptors to post-stroke neuroinflammation.
\end{abstract}

Methods: To investigate the effects of $\beta 2$-adrenergic receptor manipulation on post-stroke neuroinflammation, we administered the $\beta 2$-adrenergic receptor agonist clenbuterol to mice $3 \mathrm{~h}$ after the onset of photothrombotic stroke. We immunostained to quantify microglia/MDM numbers and proliferation and to assess morphology and activation 3 days later. We assessed stroke outcomes by measuring infarct volume and functional motor recovery and analyzed gene expression levels of neuroinflammatory molecules. Finally, we evaluated changes in cytokine expression and microglia/MDM response in brains of mice with selective knockout of the $\beta 2$-adrenergic receptor from microglia and monocyte-lineage cells.

Results: We report that clenbuterol treatment after stroke onset causes enlarged microglia/MDMs and impairs their proliferation, resulting in reduced numbers of these cells in the peri-infarct cortex by 1.7 -fold at 3 days after stroke. These changes in microglia/MDMs were associated with increased infarct volume in clenbuterol-treated animals. In mice that had the $\beta 2$-adrenergic receptor specifically knocked out of microglia/MDMs, there was no change in morphology or numbers of these cells after stroke. However, knockdown of $\beta 2$-adrenergic receptors in microglia and MDMs resulted in increased expression of TNFa and IL-10 in peri-infarct tissue, while stimulation of $\beta 2$-adrenergic receptors with clenbuterol had the opposite effect, suppressing TNFa and IL-10 expression.

(Continued on next page)

\footnotetext{
* Correspondence: marion.buckwalter@stanford.edu

${ }^{1}$ Department of Neurology and Neurological Sciences, Stanford School of

Medicine, Palo Alto, Stanford, CA 94305, USA

${ }^{2}$ Department of Neurosurgery, Stanford School of Medicine, Palo Alto,

Stanford, CA 94305, USA
}

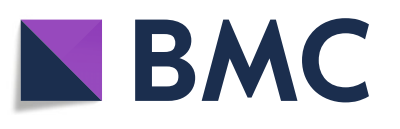

(c) The Author(s). 2019 Open Access This article is distributed under the terms of the Creative Commons Attribution 4.0 International License (http://creativecommons.org/licenses/by/4.0/), which permits unrestricted use, distribution, and reproduction in any medium, provided you give appropriate credit to the original author(s) and the source, provide a link to the Creative Commons license, and indicate if changes were made. The Creative Commons Public Domain Dedication waiver (http://creativecommons.org/publicdomain/zero/1.0/) applies to the data made available in this article, unless otherwise stated. 


\begin{abstract}
(Continued from previous page)
Conclusions: We identified $\beta 2$-adrenergic receptor signaling as an important regulator of the neuroimmune response after ischemic stroke. Increased $\beta 2$-adrenergic signaling after stroke onset generally suppressed the microglia/MDM response, reducing upregulation of both pro- and anti-inflammatory cytokines, and increasing stroke size. In contrast, diminished $\beta 2$-adrenergic signaling in microglia/MDMs augmented both pro- and anti-inflammatory cytokine expression after stroke. The $\beta 2$-adrenergic receptor may therefore present a therapeutic target for improving the post-stroke neuroinflammatory and repair process.
\end{abstract}

Keywords: Beta2-adrenergic receptor, Ischemic stroke, Microglia, Macrophage, Neuroinflammation, TNFa, Autonomic, Sympathetic, Infarct

\section{Background}

The brain's inflammatory response to ischemic stroke has significant consequences for secondary neuronal death, effective resolution of the ischemic injury, and stroke outcomes $[1,2]$. Thus, defining the endogenous signals that regulate brain inflammation is essential. One such potentially important signal is the sympathetic nervous system. Sympathetic outflow is elevated after stroke in proportion to stroke size, resulting in increased epinephrine and norepinephrine in the blood and cerebrospinal fluid of stroke patients [3-5]. Clinical care of stroke patients also involves amplifying or reducing blood pressure with drugs that act on the adrenergic receptors that bind epinephrine and norepinephrine [6]. This makes it critical to understand how adrenergic signaling affects the immune response to stroke.

The immune effects of adrenergic signaling are primarily transmitted by $\beta 2$-adrenergic receptors, which are highly expressed on all major immune cell subtypes [7]. $\beta 2$-adrenergic signaling has context-dependent consequences, in some cases suppressing immune cell activation $[5,8]$ and in others causing immune cell depletion [9]. Previous studies investigating how $\beta 2$-adrenergic receptor signaling affects stroke-induced neuronal death and neuroinflammation in the brain focused on manipulation of the receptor prior to stroke only and yielded conflicting results [10-14]. Pre-treating with a selective $\beta 2$ agonist reduces infarct size in mice [10] and rats [10-12], while global knockout of the $\beta 2$-adrenergic receptor or pre-treatment with the $\beta 2$-adrenergic receptor selective antagonist ICI 118,551 also reduces infarct size, improves behavioral outcome, and reduces pro-inflammatory gene expression $[13,14]$. These studies did not distinguish whether altered $\beta 2$-adrenergic signaling directly affects initial stroke size, or if it regulates neuroinflammation and subsequent neuronal loss. These studies also did not examine effects on the immune cells central to the stroke response: microglia and blood monocyte-derived macrophages (MDMs).

Indeed, although it is well-documented that immune cells in the periphery are regulated by the sympathetic nervous system and $\beta 2$-adrenergic signaling, relatively little is known about the effect of $\beta 2$-adrenergic signaling on immune responses within the central nervous system. Microglia and MDMs dominate the neuroimmune response in the sub-acute phase after ischemic stroke and therefore have a direct impact on neuronal survival and injury resolution $[15,16]$. Both of these cell populations express functional $\beta 2$-adrenergic receptors [17-19]; in fact, microglia express the $\beta 2$-adrenergic receptor about ten-fold more highly than any other cell type in the brain [20]. In cultured microglial cells, norepinephrine suppresses LPS-induced NF- $\mathrm{KB}$ signaling and production of pro-inflammatory cytokines including iNOS, IL-1 $\beta$ [21-23], tumor necrosis factor- $\alpha$ (TNF $\alpha$ ), and IL-6 [18, 24, 25]. Loss of adrenergic signaling in models of neurodegeneration was shown to impair the microglial disease response $[25,26]$. However, the effects of $\beta 2$-adrenergic signaling on the microglial/MDM response to brain injury such as ischemic stroke have not been investigated.

The aim of this study was thus to identify the role of microglial and macrophage $\beta 2$-adrenergic signaling in modulating neuroinflammation and outcomes in a rodent model of ischemic stroke. We isolated the effects of $\beta 2$-adrenergic stimulation on post-stroke neuroinflammation by treating mice with the brain-penetrant $\beta 2$-adrenergic receptor agonist clenbuterol after stroke onset. To specifically investigate the role of microglia/ MDM $\beta 2$-adrenergic signaling on post-stroke neuroinflammation, we induced stroke in a mouse model with selective knockout of the $\beta 2$-adrenergic receptor from microglia and monocyte-lineage cells. Using these models, we assessed activation, proliferation, and morphology of microglia/MDMs as well as infarct size, expression of inflammatory mediators, and stroke outcomes.

\section{Methods}

\section{Animals}

All animal use was in accordance with protocols approved by the Stanford University Institutional Animal 
Care and Use Committee. Male C57BL/6J mice (stock number: 000664) and $\mathrm{Cx} 3 \mathrm{cr} 1^{\mathrm{CreER}}$ mice (specific strain name: B6.129P2(Cg)-Cx3cr1 $1^{\text {tm2.1(cre/ERT2)Litt/WganJ) were }}$ purchased from The Jackson Laboratories (Bar Harbor, ME). Adrb2 $2^{\text {flox/flox }}$ mice were obtained from the Gerard Karsenty lab at Columbia University. Mice were housed in a temperature-controlled 12-h light-dark alternating facility, with ad libitum access to food and water. All experiments were performed with 8-11-week-old male mice, except behavioral assessments which were performed in 10-week-old female mice. To generate mice with conditional knockout of the $\beta 2$-adrenergic receptor from microglia and monocyte lineage cells, we bred Cx3cr1 ${ }^{\text {CreER }}$ animals with Adrb2 ${ }^{\text {flox/flox }}$ animals. Experimental Adrb2 $2^{\mathrm{cKO}}$ mice were homozygous for the Adrb2flox/flox allele and heterozygous for the Cx3cr1 $1^{\text {CreER }}$ knock-in allele; littermate control Adrb $2^{\mathrm{WT}}$ mice were homozygous for the Adrb2 $2^{\text {flox/flox }}$ allele and homozygous for wild-type Cx3cr1. Both groups were given doses of $0.125 \mathrm{mg} / \mathrm{kg}$ tamoxifen in corn oil via oral gavage on three consecutive days to induce knockout of the gene for the $\beta 2$-adrenergic receptor in Adrb2 ${ }^{\text {СКO }}$ mice. Stroke surgeries were performed 5 days after the last tamoxifen dose to allow sufficient time for maximal recombination but not enough time for blood monocytes to turn over [27], ensuring that microglia in addition to the majority of blood monocytes would lack the $\beta 2$-adrenergic receptor at the time of stroke.

\section{Photothrombotic stroke}

The photothrombotic stroke model of cortical ischemic injury was performed based on published protocols [28]. Animals were anesthetized with $2 \%$ Isoflurane in $2 \mathrm{~L} /$ min $100 \%$ oxygen and maintained at $37^{\circ} \mathrm{C}$ both during surgery and recovery using a feedback-controlled heating blanket. Mice were injected intraperitoneally (i.p.) with $80 \mathrm{mg} / \mathrm{kg}$ Rose Bengal (Sigma \#330000 5G) dissolved 10 $\mathrm{mg} / \mathrm{ml}$ in sterile saline, anesthetized, and placed in a stereotactic frame. Sham mice were given i.p. injections of sterile saline instead of Rose Bengal and underwent the same surgery as the stroke groups. A midline scalp incision was made to expose the skull, and $10 \mathrm{~min}$ after Rose Bengal or saline injection, a $1-\mathrm{mm}$ diameter Metal Halide Fiber optic light (Edmundonoptics \#56371) was positioned directly over the right motor cortex $(0.5 \mathrm{~mm}$ anterior and $1.75 \mathrm{~mm}$ laterally to the right of Bregma) for exactly $15 \mathrm{~min}$ to produce cortical infarction. Mice were concurrently injected with $25 \mathrm{mg} / \mathrm{kg}$ cefazolin (VWR \#89149-888) and 1 $\mathrm{mg} / \mathrm{kg}$ of buprenorphine SR (Zoopharm, Windsor, $\mathrm{CO})$ to prevent infection and for pain management, respectively. The scalp incision was resealed using Surgi-lock tissue adhesive (Meridian, Allegan, MI).

\section{Drug treatment}

Clenbuterol (Sigma C5423) was administered to mice 3 $\mathrm{h}$ after stroke via subcutaneous pumps with a simultaneous bolus injection to immediately boost the amount of circulating drug in the blood and to allow the drug concentration to reach steady state more quickly. Bolus injections of $1 \mathrm{mg} / \mathrm{kg}$ clenbuterol dissolved in sterile $0.9 \%$ saline were delivered intraperitoneally using a volume of $0.01 \mathrm{~mL}$ per gram of mouse weight. Alzet 1003D drug delivery pumps (Alzet, Cupertino, CA) were filled with $0.000833 \mathrm{~g} / \mathrm{mL}$ clenbuterol solution to achieve a delivery rate of $1 \mathrm{mg} / \mathrm{kg} /$ day and were implanted according to manufacturer instructions $3 \mathrm{~h}$ after stroke. Mice in the control group were injected with $0.9 \%$ sterile saline and implanted with a pump filled with $0.9 \%$ saline. Mice sacrificed at the acute 4 -h time point received bolus injections but not subcutaneous pumps. Mice that underwent behavioral assessment were given $1 \mathrm{mg} / \mathrm{kg}$ i.p. injections of clenbuterol $3 \mathrm{~h}$ post-stroke and subsequently every $24 \mathrm{~h}$ for the first week of testing instead of using subcutaneous pump implants, in order to prevent impairment of performance on motor testing. Mice used for histological analysis were injected i.p. with $50 \mathrm{mg} / \mathrm{kg}$ bromodeoxyuridine (BrdU: Sigma B5002) dissolved in sterile PBS $24 \mathrm{~h}$ prior to sacrifice.

\section{Immunohistochemistry}

All animals were sacrificed at 3 days post-stroke for immunohistochemistry. Mice were sedated with chloral hydrate and perfused with $0.9 \% \mathrm{NaCl}$ containing $10 \mathrm{U} / \mathrm{mL}$ heparin. The brains were collected and drop-fixed in $4 \%$ PFA in phosphate buffer for $24 \mathrm{~h}$ at $4{ }^{\circ} \mathrm{C}$, then were preserved in $30 \%$ sucrose in PBS. A freezing microtome (Microm HM430) was used to collect $40-\mu \mathrm{m}$-thick coronal brain sections sequentially into 12 tubes. Brain sections were stored in cryoprotectant medium (30\% glycerin, $30 \%$ ethylene glycol, and $40 \% 0.5 \mathrm{M}$ sodium phosphate buffer) at $20^{\circ} \mathrm{C}$ until processing. Standard immunohistochemistry procedures were used to stain free-floating sections. Briefly, sections were blocked with $3 \%$ donkey (Millipore, \#S30-100 mL), or rabbit (Vector, $\#$ S-5000) serum for $1 \mathrm{~h}$. Tissue was then incubated at $4{ }^{\circ} \mathrm{C}$ overnight in primary antibody: anti-Iba1 (rabbit, 1:1000, Wako 019-19,741), anti-BrdU (rat, 1:5000, Abcam Ab6326), biotinylated anti-NeuN (mouse, 1:500, Millipore MAB377B), or anti-CD68 (rat, 1:1000, BioRad MCA1957S). Iba1 and BrdU were labeled with fluorescent secondary antibodies (donkey anti-rabbit IgG, 1:200, Thermo-Fisher A-21206; donkey anti-rat IgG, 1:200, Jackson ImmunoResearch 712-165-153), mounted onto glass slides, and coverslipped using Vectashield HardSet Mounting Medium (Vector Laboratories, H-1400). For CD68 staining, tissue was incubated for $1 \mathrm{~h}$ in secondary antibody (rabbit anti-rat IgG, 1:500, Vector Laboratories 
BA-4001). For both CD68 and NeuN stains, tissue was treated with Avidin-Biotin Complex solution (Vector, \#PK-6100) for $1 \mathrm{~h}$ and treated for 5 min with filtered DAB (Sigma, \#D5905) solution. Finally, sections were mounted onto glass slides, air-dried overnight, and then coverslipped with Entellan (Electron Microscopy Sciences 14,800). NeuN-labeled slides were rehydrated and stained with Cresyl violet prior to coverslipping.

\section{Image acquisition and quantification \\ BrdU/lba1 colocalization}

Z-stacks were taken at $\times 40$ magnification using a Leica confocal microscope in the medial peri-infarct region of the cortex, defined as the area equidistant between the stroke border and the midline of the brain, at least one view field above the corpus callosum and with images spaced vertically one view field apart. Two z-stacks per brain section and two brain sections per mouse were used for analysis. Sections were excluded from the analysis if they showed irregular immunostaining, which was either high background immunofluorescence or failure of the BrdU stain to label the subventricular zone, which we used as an internal positive control. Iba1+ cells, BrdU+ cells, and Iba1/BrdU double-positive cells were quantified in the z-stacks using ImageJ software, and percent proliferation was calculated by dividing the total number of Iba1+ BrdU+ double-positive cells by the number of Iba1+ cells. All imaging and quantification and was performed by an experimenter blinded to experimental group.

\section{Iba1 fluorescence area}

Four z-stacks per brain section in two brain sections per mouse were taken of Iba1-stained cells. Confocal z-stacks of Iba1-stained cells were maximum intensity projected, converted to 8-bit, background-subtracted, and thresholded using the default method in ImageJ software. The percent of the image area covered by Iba1 immunostaining was averaged across images for each individual animal.

\section{CD68 immunohistochemistry}

Brightfield images were taken at $\times 20$ magnification using a Keyence microscope in the medial and lateral peri-infarct cortex (along the edge of the stroke border). One image was taken per region per tissue section in five sequential sections per animal. Images were converted to 8-bit in Image J software and then thresholded using the default method. For each region, the percent of the image area covered by CD68 immunostaining was averaged across images for each individual animal. For qualitative scoring, infarct border images (1 image per brain section, 5 sections per animal) were evaluated by a blinded experimenter. Density of CD68+ cells was given a score of 1 (most sparse), 2 (average density), or 3 (extremely dense). Size of CD68+ cells was given a score of 1 (smallest), 2 (average size), or 3 (largest). Scores per animal were averaged for each measure.

\section{Infarct volume analysis of NeuN and cresyl violet immunostains}

Slides were scanned using a Silverfast PathScan Enabler IV Slide Scanner. The stroke area, ipsilateral ventricle area, ipsilateral hemisphere total area, contralateral ventricle area, and contralateral hemisphere total area were traced in ImageJ software. In order to account for brain swelling following ischemic injury and to minimize variance, normalized stroke volume was calculated as the stroke area divided by the area of the contralateral brain hemisphere with the contralateral ventricle area subtracted. This value was averaged across the nine sections centered on the maximal area of the stroke for each animal. All quantification was performed by an experimenter blinded to experimental group.

\section{RNA extraction, reverse transcription, and real-time quantitative PCR}

Mice were sacrificed at either an acute ( $4 \mathrm{~h}$ after stroke) or sub-acute ( 3 days after stroke) time point. Peri-infarct cortical tissue and stroke core was rapidly dissected, flash-frozen using liquid nitrogen, and stored at $-80^{\circ} \mathrm{C}$ to prevent RNA degradation. Peri-infarct cortex was defined as the area of cortical tissue within a $2.5 \mathrm{~mm}$ radius of the stroke core at the time of dissection. Tissue was homogenized, and RNA was extracted with TRizol reagent (ThermoFisher 15596026). RNA $(1.5 \mu \mathrm{g})$ was reverse-transcribed into cDNA using the High-Capacity cDNA Reverse Transcription Kit (ThermoFisher 4368814) according to manufacturer's instructions. We performed qPCR using SYBR Green (Qiagen 204,145) and the QuantStudio 6 Flex Real-Time PCR System. We quantified the expression of the following genes: Adrb2, TNF $\alpha$, iNOS, IL-10, Ym1, and Mki67 (Table 1). We used Gapdh as a reference gene and calculated relative gene expression using the $\operatorname{ddC}(\mathrm{t})$ method [29].

\section{Behavioral assessment}

We tested functional recovery following photothrombotic stroke of the motor cortex using the foot fault task, gridwalk task, and the rotating beam task [30, 31]. We measured missed steps of the contralateral forepaw on the foot fault task, and the distance traveled before falling on the rotating beam task. Mice underwent handling, one habituation day, two pretraining days, and baseline behavioral testing prior to photothrombotic stroke. Behavior was then tested on these tasks on days $1,3,7,14,21$, and 28 following photothrombotic stroke. Animals were placed on the foot fault gridwalk 
Table 1 Primer sequences utilized for RT-qPCR analysis

\begin{tabular}{|c|c|c|c|}
\hline Gene & GenBank accession number & Gene name & Primer sequence $\left(5^{\prime}-3^{\prime}\right)$ \\
\hline \multirow[t]{2}{*}{ Adrb2 } & NM_007420.3 & Adrenergic receptor beta-2 & Forward: TCGAGCGACTACAAACCGTC \\
\hline & & & Reverse: CCAGAACTCGCACCAGAAGT \\
\hline \multirow[t]{2}{*}{ TNFa } & NM_013693.3 & Tumor necrosis factor-alpha & Forward: TAGCCCACGTCGTAGCAAAC \\
\hline & & & Reverse: GTCTTTGAGATCCATGCCGTTG \\
\hline \multirow[t]{2}{*}{ iNOS } & NM_001313922.1 & Inducible nitric oxide synthase & Forward: TGACGGCAAACATGACTTCAG \\
\hline & & & Reverse: GCCATCGGGCATCTGGTA \\
\hline \multirow[t]{2}{*}{$\mathrm{IL}-10$} & NM_010548.2 & Interleukin 10 & Forward: CTGGACAACATACTGCTAACCG \\
\hline & & & Reverse: GGGCATCACTTCTACCAGGTAA \\
\hline \multirow[t]{2}{*}{ Ym1 } & NM_009892.3 & Chitinase-like 3 & Forward: AGACTTGCGTGACTATGAAGCATT \\
\hline & & & Reverse: GCAGGTCCAAACTTCCATCCTC \\
\hline \multirow[t]{2}{*}{ Mki67 } & NM_001081117.2 & Marker of proliferation Ki-67 & Forward: ATCATTGACCGCTCCTITAGGT \\
\hline & & & Reverse: GCTCGCCTTGATGGTTCCT \\
\hline \multirow[t]{2}{*}{ Gapdh } & NM_001289726.1 & Glyceraldehyde-3-phosphate dehydrogenase & Forward: ATCATTGACCGCTCCTITAGGT \\
\hline & & & Reverse: GCTCGCCTTGATGGTTCCT \\
\hline
\end{tabular}

apparatus and were allowed to explore freely for $5 \mathrm{~min}$, and the number of contralateral forelimb faults was recorded. Animals were placed on the rotating beam and the distance covered prior to falling was recorded, for four trials each testing day.

\section{Epinephrine and norepinephrine ELISA}

We measured levels of epinephrine and norepinephrine in plasma of mice 4 and $24 \mathrm{~h}$ after photothrombotic stroke or sham surgery using a 2-Catecholamine [Adrenaline-Noradrenaline] Research ELISA kit (Rocky Mountain Diagnostics, Colorado Springs, CO). Briefly, plasma was obtained from whole blood collected via cardiac puncture from deeply anesthetized mice and EDTA and sodium metabisulfite were added to plasma samples at concentrations of $1 \mathrm{mM}$ and $4 \mathrm{mM}$, respectively. Plasma samples were then diluted 1:2 and were assayed in duplicate according to the manufacturer's instructions. Three samples were excluded from both the norepinephrine and epinephrine plasma analyses because they were identified to be statistical outliers using published methods [32].

\section{Blood pressure measurement}

Blood pressure was recorded using the non-invasive tail cuff Visitech Systems BP-2000 Blood Pressure Recording System (Apex, NC). Mice were acclimatized to the recording device and procedure for two consecutive days preceding the testing day. Measurements taken on the second acclimatization day were used as baseline blood pressure measurements for each animal. On the testing day, the animals were allowed to adjust to the recording room in their home cages for $1 \mathrm{~h}$, then received a single i.p. injection of either $1 \mathrm{mg} / \mathrm{kg}$ clenbuterol or sterile saline. At $4 \mathrm{~h}$ and $7 \mathrm{~h}$ post-injection, systolic blood pressure, diastolic blood pressure, pulse, and mean arterial blood pressure were measured according to the device manufacturer's instructions and were processed using BP-2000 software. Fifteen measurements were taken for each animal at each time point, and the value for each animal was calculated by averaging the last 10 measurements taken. Individual measurements that were outliers were identified and removed using published methods [32].

\section{Statistical analysis}

Data was processed using GraphPad Prism 7 software. For comparisons between two groups, a two-tailed Student's $t$ test was used. A Mann-Whitney test with Dunn's multiple comparisons test was used for data that was not normally distributed. For experiments with more than two groups, a one- or two-way ANOVA test was used with Tukey's multiple comparisons test for post hoc analysis. All data are presented as mean \pm SEM. Experiments were designed using power analyses to determine sample sizes based on expected variances and group differences. All animals were randomized between experimental groups and experimenters were blinded to group assignments.

\section{Results}

\section{Plasma norepinephrine concentration after} photothrombotic stroke

Previous studies have reported an increase in plasma or serum levels of epinephrine and norepinephrine following stroke in humans [3,33] and in rodent models [5, 9], dependent on stroke severity. We therefore asked if sympathetic catecholamines would be upregulated in plasma 
in the photothrombotic model of ischemic stroke in mice. There was substantial variability between animals in norepinephrine and epinephrine plasma measurements, and we did not see significant changes in concentrations of either catecholamine at either 4 or $24 \mathrm{~h}$ after stroke compared to sham. There did appear to be a slight but non-significant increase in plasma norepinephrine $24 \mathrm{~h}$ after stroke $(6.11 \pm 1.10 \mathrm{ng} / \mathrm{mL}$; mean \pm SEM; $n=5)$ compared to sham $(3.53 \pm 0.68 \mathrm{ng} / \mathrm{mL}$; mean \pm SEM; $n=5$; Dunn's multiple comparisons test, $p=0.4127)$.

\section{Increased $\beta 2$-adrenergic receptor stimulation after ischemic stroke alters microglia/MDM numbers and morphology}

To investigate how augmenting $\beta 2$-adrenergic signaling after ischemic stroke influences the microglial and MDM response to stroke, we treated wild-type mice with a brain-penetrant $\beta 2$-adrenergic receptor-specific agonist, clenbuterol. We administered clenbuterol or saline (vehicle control) $3 \mathrm{~h}$ after induction of photothrombotic cortical stroke and collected brain tissue at 3 days post-stroke (Fig. 1a). We first analyzed if clenbuterol treatment after ischemic stroke altered macrophage activation and/or numbers in the cortex by immunostaining for CD68, a marker for activated microglia and macrophages. There was no difference between clenbuterol-treated and saline-treated mice in the percentage area covered by $\mathrm{CD} 68+$ macrophages in the stroke border (Fig. 1b) or peri-infarct cortex (Fig. 1c). However, we observed qualitatively that CD68 + cells appeared larger and sparser in the brains of clenbuterol-treated mice. Rating of the size and density of CD68+ cells in the stroke border by a blinded experimenter confirmed that microglia/MDMs were significantly larger and less dense in the brains of clenbuterol-treated mice 3 days after stroke (Fig. 1d), indicating that increased $\beta 2$-adrenergic stimulation after stroke may induce hypertrophy and reduce cell numbers of microglia and/or MDMs near the infarct.

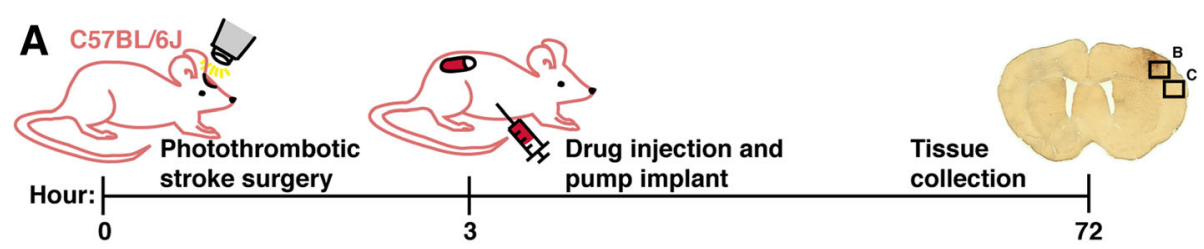

B

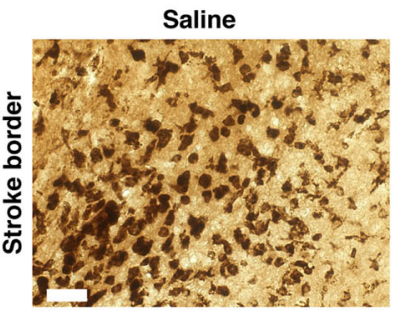

C

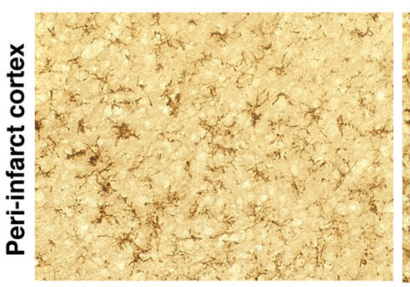

D

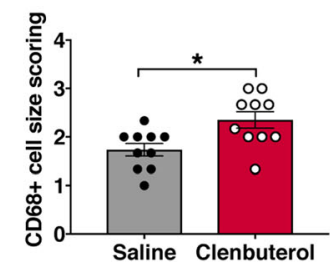

Clenbuterol
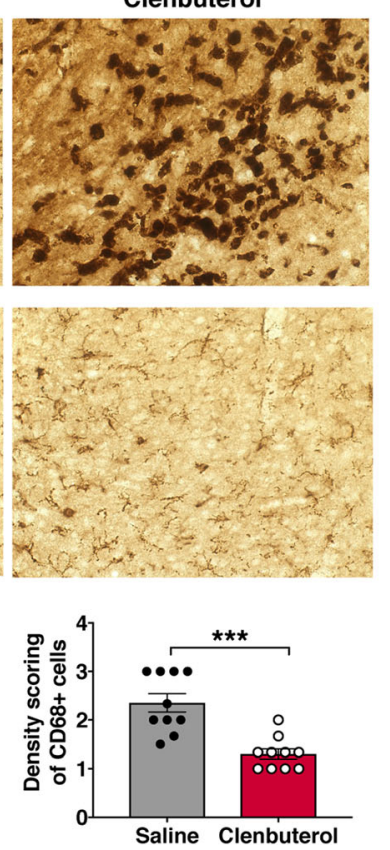
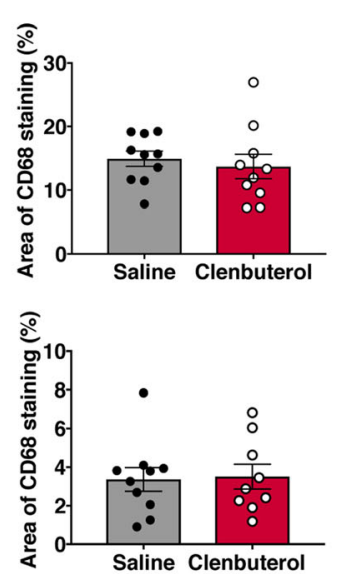

Fig. 1 Clenbuterol administration after stroke reduces macrophage density and increases macrophage size. a Experimental design. Three hours after photothrombotic cortical stroke, C57BL/6J mice received clenbuterol or saline vehicle control, $1 \mathrm{mg} / \mathrm{kg}$ i.p. bolus injection, and $1 \mathrm{mg} / \mathrm{kg} / \mathrm{day}$ via subcutaneous pump. Mice were sacrificed 3 days post-stroke. b, c Representative images of CD68-immunopositive cells in the stroke border (b) and peri-infarct cortex (c) of clenbuterol- or saline-treated mice. Quantification of the percent image area covered by CD68 immunostaining is shown to the right of the photomicrographs, Student's $t$ test. $\mathbf{d}$ Qualitative scoring of size and density of CD68+ cells in the stroke border, MannWhitney test. $n=8-10$ mice per group. Bars, mean \pm SEM; ${ }^{*} p<0.05$, ${ }^{* * *} p<0.001$; scale bar, $50 \mu \mathrm{m}$ 
CD68 is a lysosomal protein with high expression in activated microglia and macrophages, but low expression in resting microglia, and thus may not demonstrate cell size accurately. In order to quantify the effect of post-stroke clenbuterol treatment on total microglia/ MDM numbers and size, we therefore immunostained for the calcium-binding protein Iba1, which is a cell surface protein on both resting and activated microglial cells as well as MDMs. We counted Iba1-positive cells in confocal z-stacks taken in the peri-infarct cortex, which revealed a 1.7 -fold reduction in Iba1+ cell density in the peri-infarct cortex of clenbuterol-treated mice compared to saline-treated mice 3 days after photothrombotic stroke (Fig. 2a, b). Similar to our observations of CD68+ cells, individual Iba1+ cells in stroke cortex of clenbuterol-treated mice appeared hypertrophic. We quantified the area covered by Iba1+ staining per cell and found that it was indeed approximately $14 \%$ greater in clenbuterol-treated mice than in saline-treated mice (Fig. 2c).

To test if the reduction in numbers of Iba1+ cells in the brains of clenbuterol-treated mice was due to reduced proliferation, we injected mice with the thymidine analog BrdU $24 \mathrm{~h}$ prior to sacrifice at 3 days post-stroke and then quantified Iba1+ cells co-labeled with BrdU. The percentage of Iba1+ cells labeled with BrdU was reduced by 2.8 -fold in the brains of clenbuterol-treated mice (Fig. 3a, b), suggesting that clenbuterol treatment following stroke reduces microglia/MDM proliferation and numbers surrounding the stroke. Consistent with the reduction in immune cell proliferation, we also observed a decrease in mRNA levels of the non-specific proliferation marker Ki67 in peri-infarct cortex (Fig. 3c). Taken together, these results indicate that increased $\beta 2$-adrenergic signaling results in impaired proliferation and hypertrophy of microglia/MDMs after stroke.

\section{Increased $\beta 2$-adrenergic stimulation after stroke onset causes infarct expansion}

Neuroinflammation after stroke affects infarct expansion and cell death, so we asked if the fewer but larger microglia in mice treated with clenbuterol after stroke were associated with changes in infarct size. At 3 days after photothrombotic stroke, clenbuterol-treated animals had 1.4-fold larger infarct volumes compared to saline-treated animals (Fig. 4a). Changes in body weight from baseline as well as spleen weight were not altered by clenbuterol treatment at this time point following stroke (data not shown). Clenbuterol can cause vasodilation by acting on $\beta 2$-adrenergic receptors expressed by blood vessels, so we evaluated if the dose used for our experiments caused changes in blood pressure in mice. Compared to baseline systolic arterial pressure, we observed a 33\% decrease at 4 $\mathrm{h}$ and a $22 \%$ decrease at $7 \mathrm{~h}$ after injection of clenbuterol

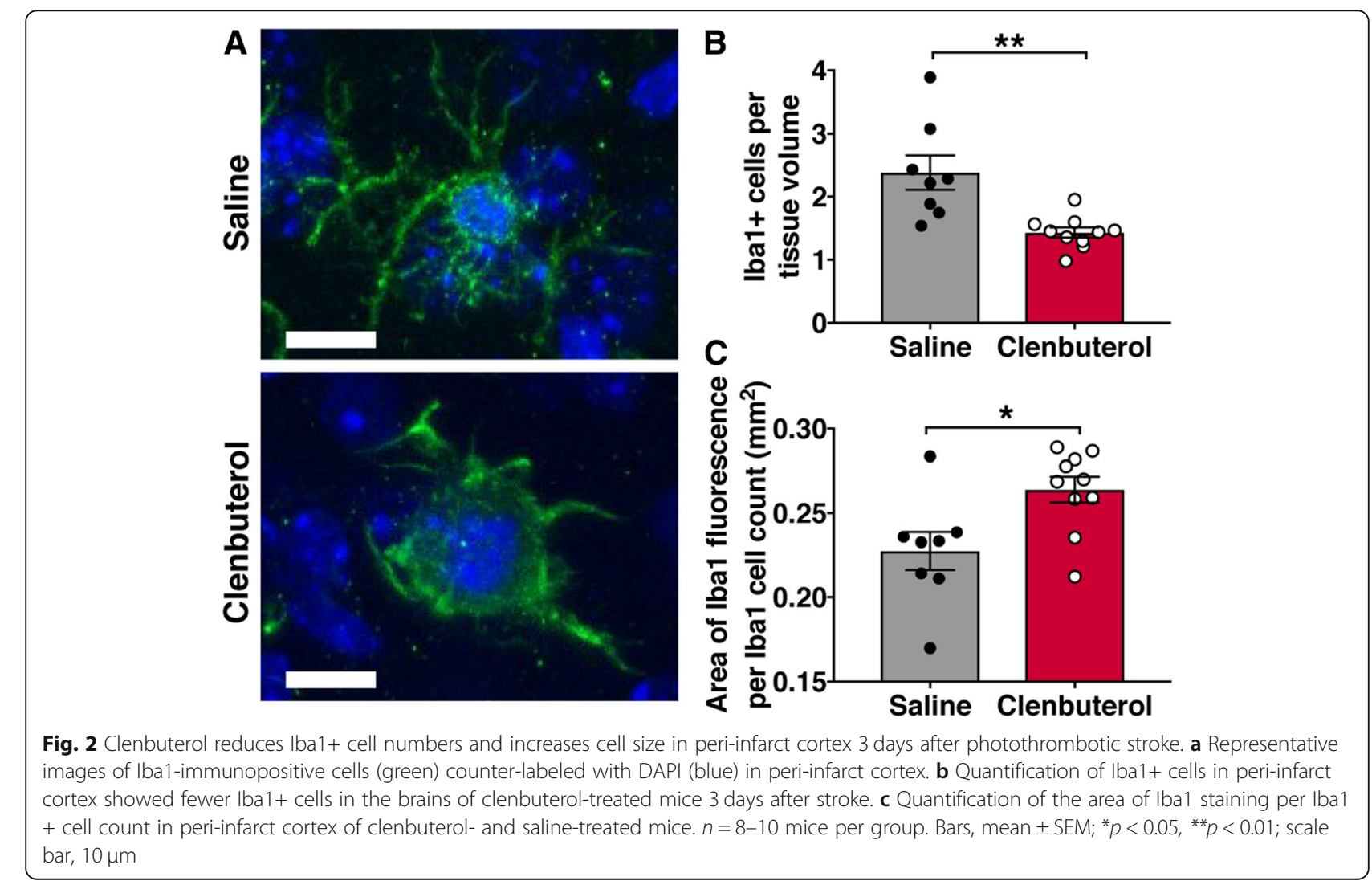



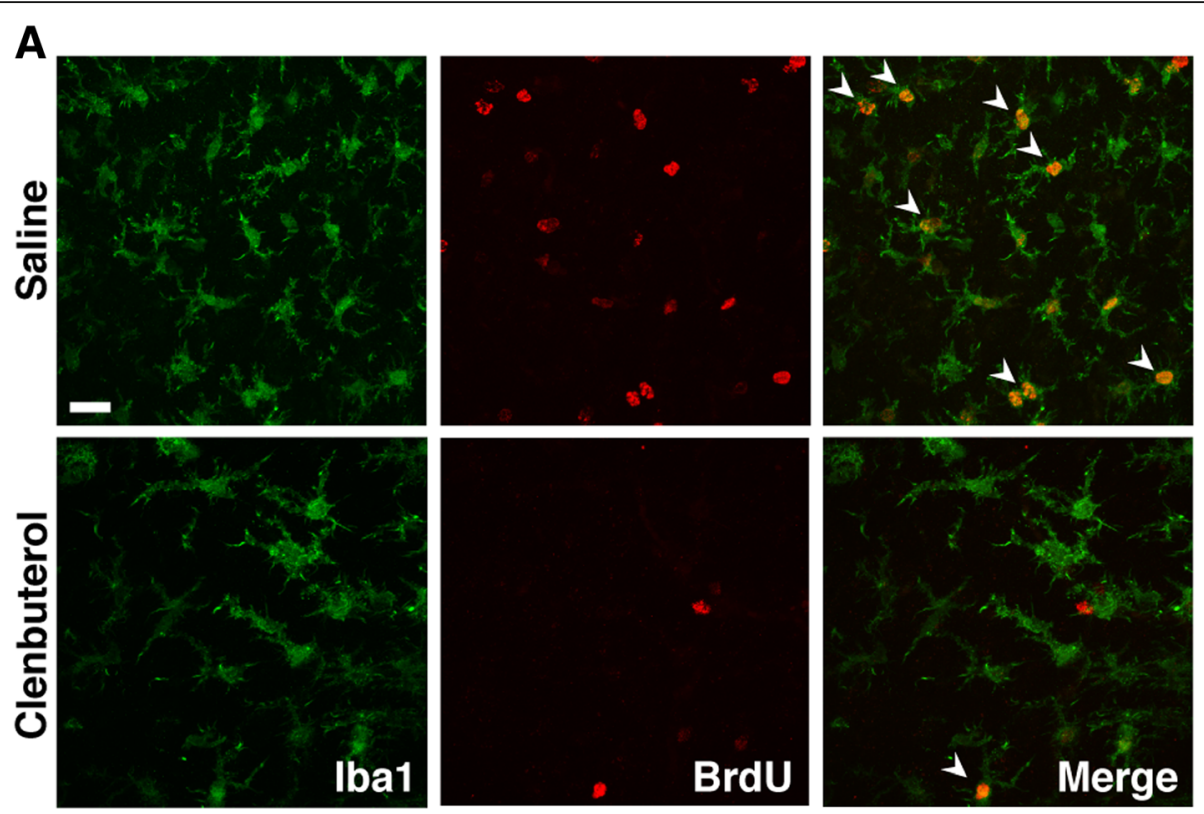

B

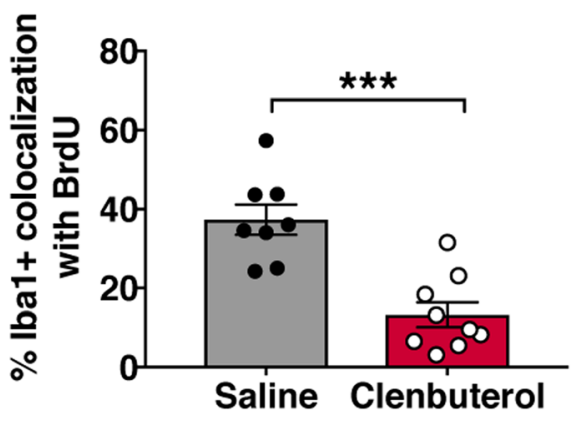

c

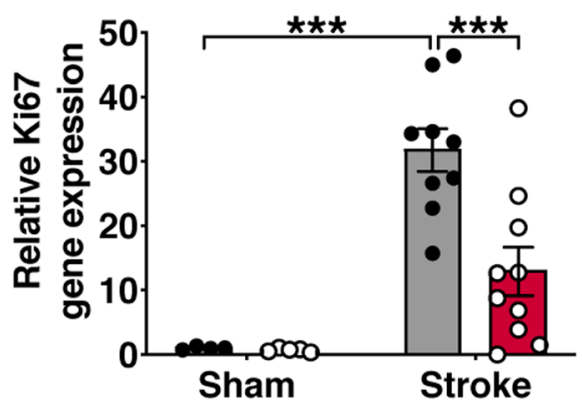

Fig. 3 Clenbuterol administration reduces proliferation of Iba1+ cells in peri-infarct cortex 3 days after photothrombotic stroke. a Representative images of Iba1 and BrdU colocalization in peri-infarct cortex. b Quantification of the percentage of Iba1+ cells co-labeled with BrdU, Student's $t$ test ( $n=8-10$ mice per group). c Ki67 gene expression relative to saline-treated sham mice in clenbuterol-treated mice compared to salinetreated mice 3 days after photothrombotic stroke, two-way ANOVA with Tukey's multiple comparison's test ( $n=5-10$ mice per group). ${ }^{* * *} p<0.001$; scale bar, $20 \mu \mathrm{m}$

(1 mg/kg i.p.; Fig. 4b). Diastolic blood pressure and mean arterial blood pressure were similarly reduced (data not shown). As expected, there was a compensatory response in heart rate, which was elevated by $34 \%$ at $4 \mathrm{~h}$ and $30 \%$ at $7 \mathrm{~h}$ after clenbuterol treatment (Fig. 4c). We also assessed forelimb motor recovery up to 28 days following photothrombotic stroke but did not observe differences in performance on the rotating beam (Fig. 4d) or the foot fault task (Fig. 4e) with single daily i.p. injections of $1 \mathrm{mg} /$ $\mathrm{kg}$ clenbuterol for the first 7 days post-stroke.

Selective knockout of the $\beta 2$-adrenergic receptor does not alter post-stroke microglia/MDM morphology

Based on our findings that increased $\beta 2$-adrenergic receptor stimulation dramatically altered morphology and proliferation of brain macrophages after ischemic stroke, we next asked if selectively knocking out the $\beta 2$-adrenergic receptor from this cell population would alter their stroke response. We generated specific knockouts for Adrb2, the gene for the $\beta 2$-adrenergic receptor, from cells of the Cx3cr1 lineage (which includes microglia and MDMs). We crossed $\mathrm{Cx} 3 \mathrm{cr}{ }^{\mathrm{CreER}}$ mice with Adrb2 floxed mice and induced knockdown by administering tamoxifen, resulting in mice lacking the $\beta 2$-adrenergic receptor only in $\mathrm{Cx} 3 \mathrm{cr} 1$ + cells $\left(\right.$ Adrb $\left.2^{\mathrm{CKO}}\right)$. We confirmed a reduction in Adrb2 mRNA in brain tissue of Adrb2 $2^{\mathrm{cKO}}$ in both sham and stroke conditions (Fig. 5).

Next, we performed photothrombotic stroke in Adrb2 ${ }^{\mathrm{cKO}}$ and Adrb2 ${ }^{\text {WT }}$ littermate controls 5 days after tamoxifen administration to allow sufficient time for Cre recombination to knock down expression of the $\beta 2$-adrenergic receptor from microglia and monocytes (Fig. 6a). To identify 

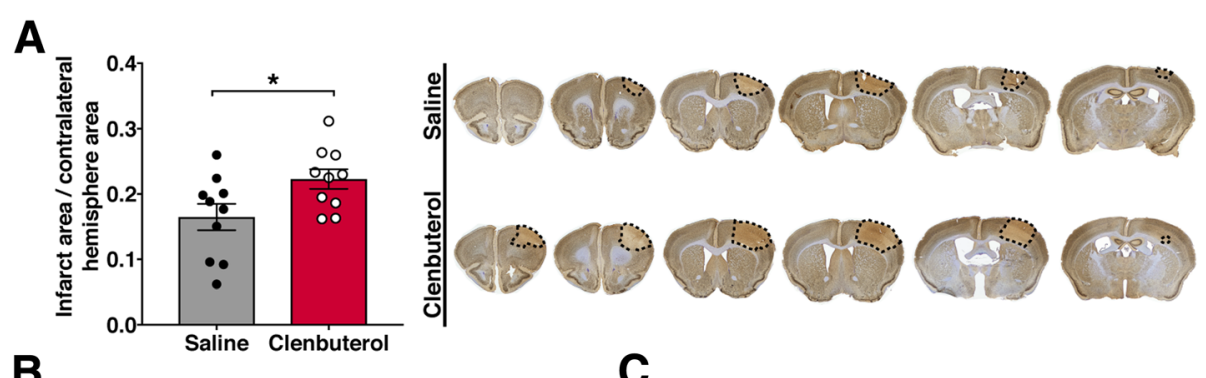

B
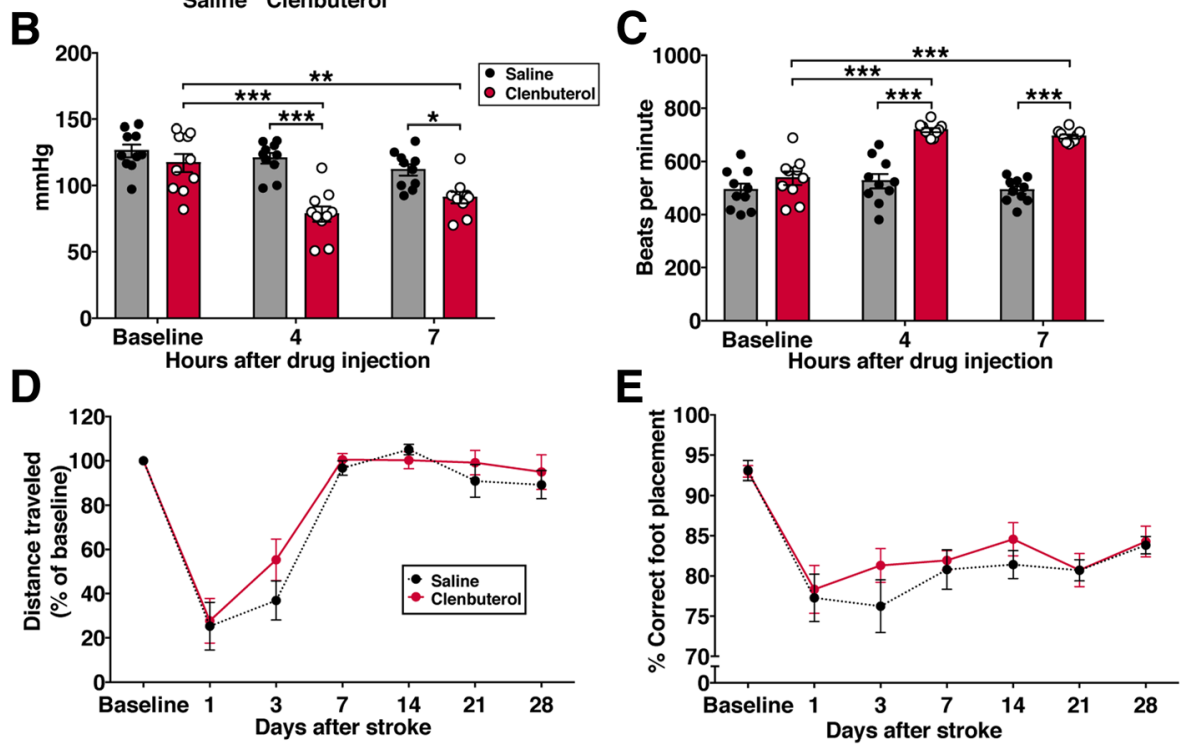

Fig. 4 Clenbuterol administration after stroke onset increases infarct size. a Quantification of infarct size (normalized to contralateral hemisphere) at 3 days, Student's $t$ test ( $n=10$ mice per group) and representative images of brain sections stained with NeuN and Cresyl Violet showing the anterior-to-posterior spread of the infarcted region at 3 days after stroke in mice treated with saline or clenbuterol. Clenbuterol was given as a 1 $\mathrm{mg} / \mathrm{kg}$ i.p. bolus injection and $1 \mathrm{mg} / \mathrm{kg} /$ day via subcutaneous pump. $\mathbf{b}$ Quantification of systolic blood pressure and $\mathbf{c}$ heart rate after a single i.p. injection of $1 \mathrm{mg} / \mathrm{kg}$ clenbuterol or saline, two-way repeated measures ANOVA with Sidak's multiple comparisons test ( $n=10$ mice per group). d Performance on the rotating beam task represented as percent of baseline distance traveled (average of four trials). e Performance on the foot fault gridwalk task, represented as correctly placed steps as percentage of total steps counted ( $n=12$ mice per group). For behavioral testing, mice were treated with a single $1 \mathrm{mg} / \mathrm{kg}$ injection of clenbuterol per day for the first 7 days after stroke. Bars and points, mean \pm SEM ${ }^{*} p<0.05$, ${ }^{* *} p<0.01,{ }^{* * *} p<0.001$

changes in microglia and MDM activation in the brains of Adrb2 ${ }^{\text {cKO }}$ mice, we once again immunostained for CD68 3 days after stroke. The percentage area covered by CD68+ cells in the stroke border or peri-infarct cortex was not different between Adrb2 $2^{\mathrm{cKO}}$ and Adrb2 ${ }^{\mathrm{WT}}$ mice (Fig. 6b, c). To determine if Adrb2 knockout had more specific effects on microglia/MDM morphology and proliferation after stroke, we also immunostained for Ibal and BrdU and quantified numbers of Iba1-positive and Iba1/ BrdU-double-positive cells in the peri-infarct cortex of $\mathrm{Adrb}^{\mathrm{cKO}}$ and Adrb2 ${ }^{\mathrm{WT}}$ mice. There was no change in numbers of Iba1+ cells (Fig. 7a, b) or the percentage of Iba1+ cells co-labeled with BrdU (Fig. 7c). In addition, we did not observe differences in infarct size or body weight in Adrb2 ${ }^{\mathrm{cKO}}$ animals 3 days after photothrombotic stroke (Fig. 7d). There were no differences in these measurements between male and female Adrb2 ${ }^{\mathrm{cKO}}$ mice (data not shown).
Taken together, this suggests that microglia and macrophage-specific Adrb2 deficiency is not itself enough to alter morphology or proliferation of microglia/MDMs or limit infarct size in the subacute period.

\section{$\beta 2$-adrenergic signaling regulates expression of inflammatory mediators after stroke}

We next wanted to ask about the functional effects of $\beta 2$-adrenergic signaling on microglia and MDMs after stroke. A key function of microglia and MDMs in response to ischemic brain injury is the production of pro-inflammatory signaling molecules such as the cytokine TNF $\alpha$ and inducible nitric oxide synthase (iNOS) [2]. To evaluate whether $\beta 2$-adrenergic signaling regulates expression of these key inflammatory molecules, we collected peri-infarct cortex at acute $(4 \mathrm{~h})$ or subacute (3 days) timepoints after stroke from mice treated 


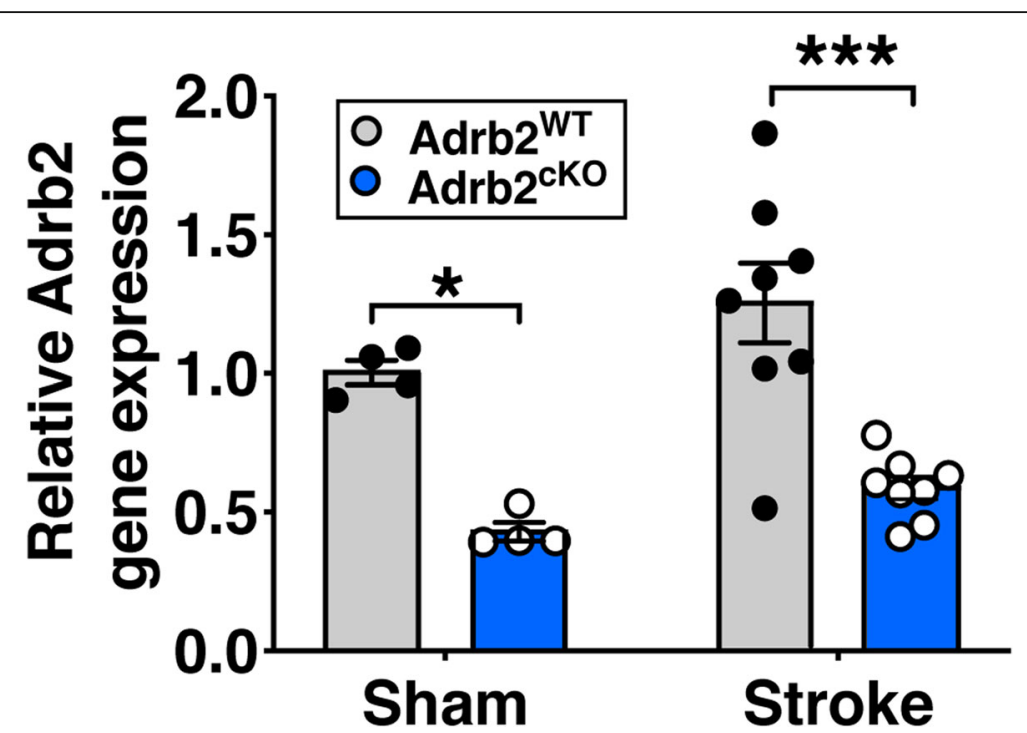

Fig. 5 Adrb2 expression is reduced in brain tissue of Adrb2 ${ }^{c k O}$ mice. Adrb2 gene expression was calculated using the ddC(t) method relative to expression in wildtype sham mice 3 days after photothrombotic stroke, two-way ANOVA with Tukey's multiple comparisons test. $n=4-8$ mice per group. Bars, mean \pm SEM; ${ }^{*} p<0.05,{ }^{* * *} p<0.001$

with saline or clenbuterol and used quantitative real-time PCR to measure cytokine mRNA levels. At $4 \mathrm{~h}$ post-stroke (Fig. 8a), which represents the acute phase of the neuro-inflammatory response and is primarily driven by brain-resident microglia, mRNA expression of TNF $\alpha$ was elevated in peri-infarct brain tissue of both salineand clenbuterol-treated mice relative to sham mice (Fig. 8b). However, TNFa expression after stroke was 1.8 -fold lower in clenbuterol-treated mice compared to saline-treated mice, indicating that increased $\beta 2$-adrenergic stimulation after stroke suppresses this pro-inflammatory cytokine. TNF $\alpha$ expression has been shown to be regulated by IL-10 [34], so we measured IL-10 mRNA to determine if clenbuterol treatment might be downregulating pro-inflammatory cytokines by upregulating anti-inflammatory gene expression. We observed a trend towards an increase in the anti-inflammatory cytokine IL-10 with clenbuterol treatment in stroke mice ( $p=0.077)$ (Fig. 8c). At this early time-point, gene expression of other pro- or anti-inflammatory

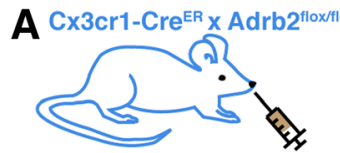

Day:<smiles>[VH][VH]</smiles>

B

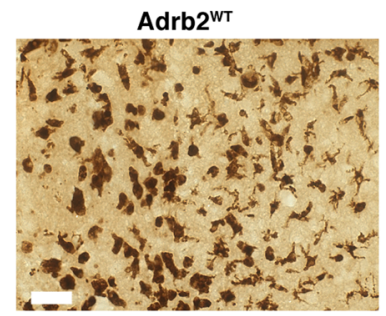

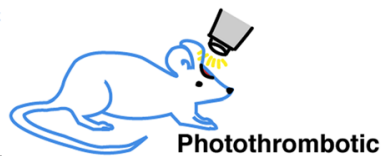
stroke surgery

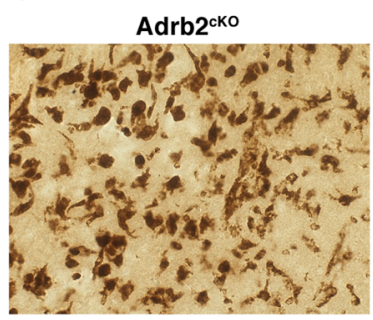

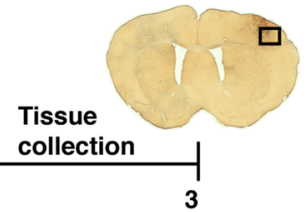

C

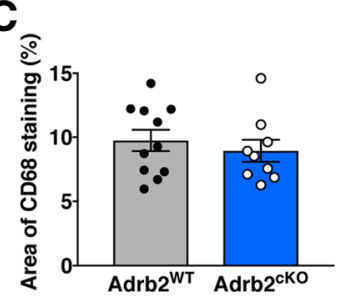

Fig. 6 Selective knockout of the $\beta 2$-adrenergic receptor in microglia/MDMs does not alter cellular morphology after stroke. a Experimental design. $\mathrm{C} \times 3 \mathrm{Cr}^{\mathrm{CreER}} \times$ Adrb2 $2^{\text {floxflox }}$ mice were treated with tamoxifen for 3 days to selectively knock down Adrb2 expression in microglia and MDMs. Five days later, we induced photothrombotic stroke, and mice were sacrificed 3 days after stroke. $\mathbf{b}$ Representative images of CD68immunopositive cells in the stroke border of Adrb2 ${ }^{\mathrm{cKO}}$ or littermate Adrb2 ${ }^{\mathrm{WT}}$ controls. c Quantification of the percent image area covered by CD68 immunostaining showed no difference between Adrb2 $2^{\mathrm{KO} O}$ and Adrb2 ${ }^{\mathrm{WT}}$ mice, Student's $t$ test. $n=9-12$ mice per group. Bars, mean \pm SEM; scale bar, $50 \mu \mathrm{m}$ 


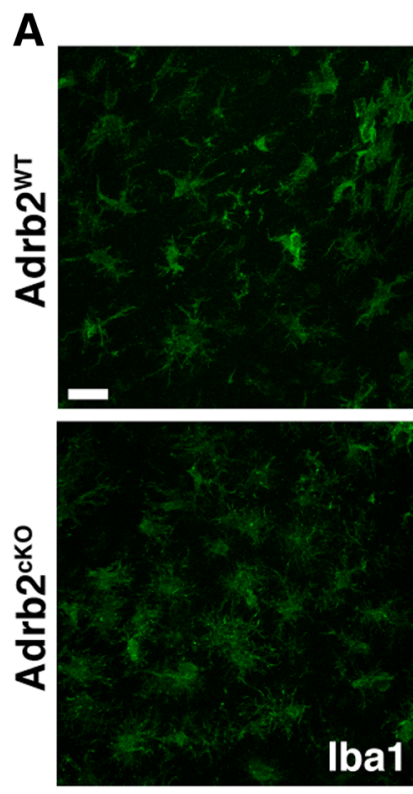

B
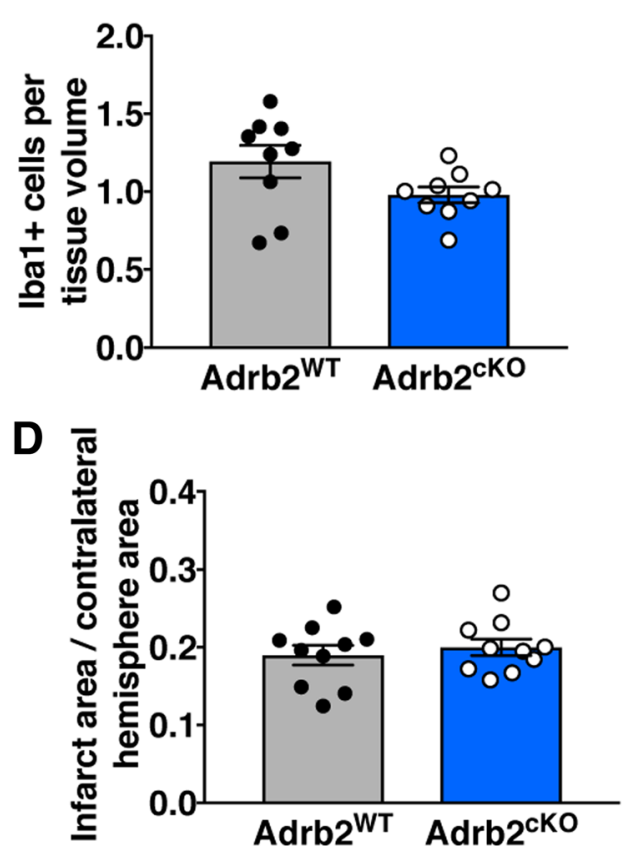
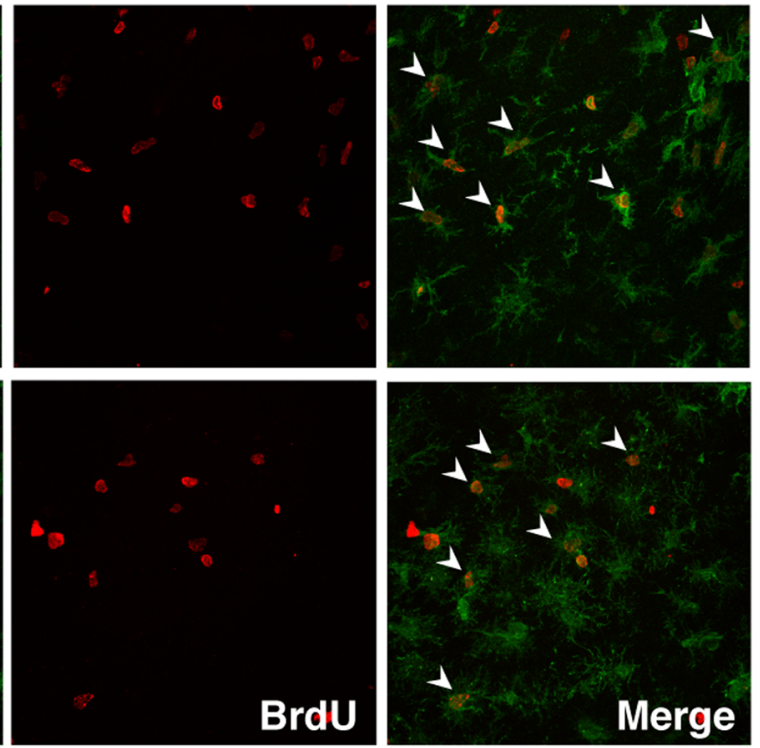

C
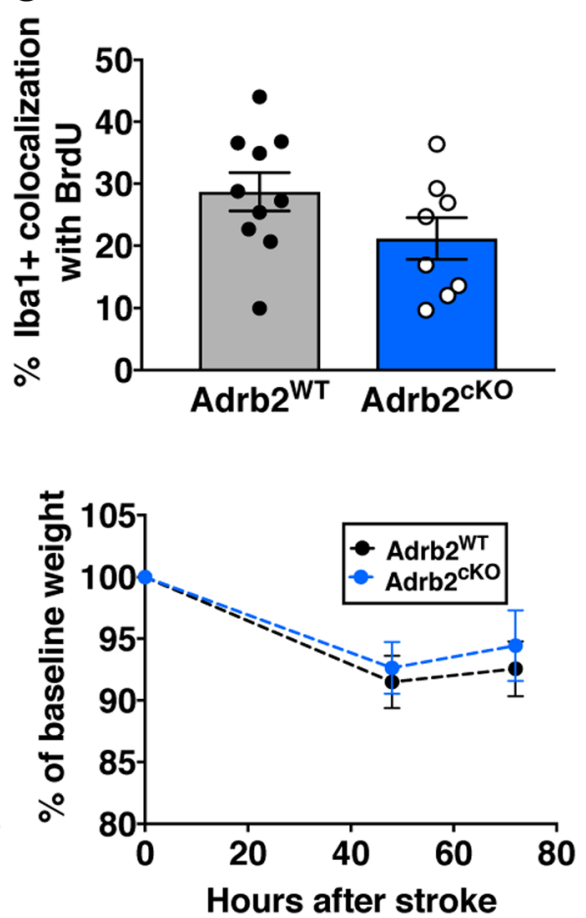

Fig. 7 Adrb $2^{c K O}$ mice do not have different lba1+ cell numbers or infarct size 3 days post-stroke compared to Adrb2 ${ }^{W T}$ mice. a Representative images of Iba1 and BrdU colocalization in peri-infarct cortex. b Quantification of Iba1+ cells in peri-infarct cortex. c Quantification of the percentage of Iba $1+$ cells co-labeled with BrdU. d Quantification of infarct size at 3 days, Student's $t$ test ( $n=8-10$ mice per group). Weight loss following stroke was also unchanged. Bars, mean \pm SEM; scale bar, $20 \mu \mathrm{m}$

molecules (iNOS and Ym1) was not affected by stroke or clenbuterol treatment (Fig. 8b, c).

In the sub-acute phase of neuroinflammation at 3 days post-stroke, TNF $\alpha$ and IL-10 mRNA expression was substantially elevated in vehicle-treated stroke mice compared to sham mice. As we had seen at $4 \mathrm{~h}$ post-stroke,
TNF $\alpha$ mRNA expression was 1.8 -fold less in peri-infarct cortex of clenbuterol-treated mice relative to saline-treated mice (Fig. 9a). However, in contrast to the trend towards increased IL-10 expression with clenbuterol treatment at $4 \mathrm{~h}$ post-stroke, IL-10 mRNA expression was actually reduced by 4.78 -fold in peri-infarct cortex 

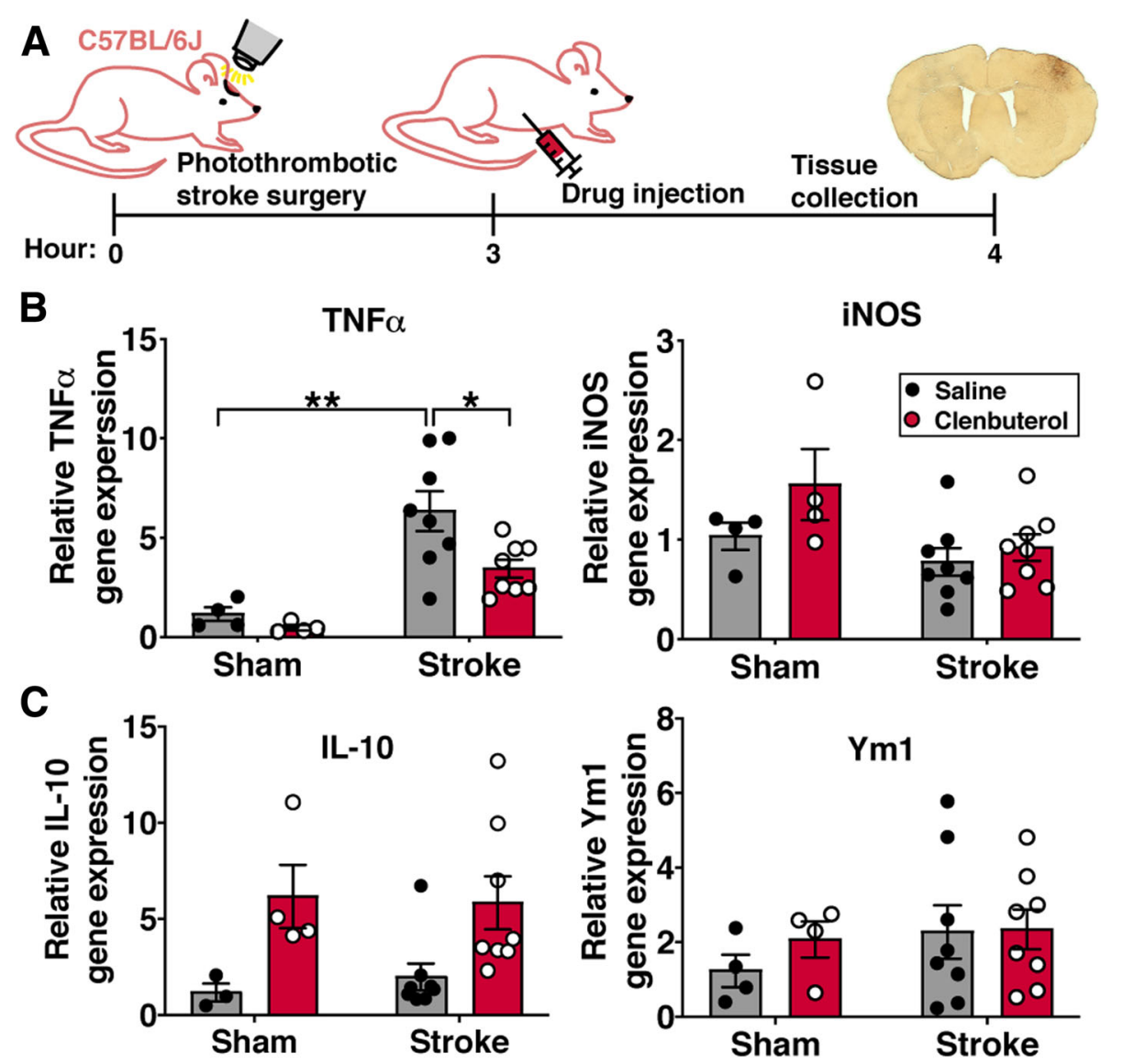

Fig. $8 \mathrm{TNFa}$ gene expression at $4 \mathrm{~h}$ post-stroke is suppressed by clenbuterol administration after stroke onset. a Experimental design. C57BL/6 mice were given $1 \mathrm{mg} / \mathrm{kg}$ clenbuterol i.p. $3 \mathrm{~h}$ after photothrombotic cortical stroke and peri-infarct cortex was collected $1 \mathrm{~h}$ later (at $4 \mathrm{~h}$ after stroke) for gene expression analysis. b Expression of pro-inflammatory genes TNFa and iNOS were normalized to expression in saline-treated sham mice. c Expression of the anti-inflammatory genes IL-10 and Ym1. Two-way ANOVA with Tukey's multiple comparisons test $(n=4-8$ mice per group). Bars, mean \pm SEM; ${ }^{*} p<0.05,{ }^{* *} p<0.01$

of clenbuterol-treated mice relative to saline-treated mice at the 3-day sub-acute time point (Fig. 9b). We hypothesized that the dramatic suppression of TNF $\alpha$ with clenbuterol treatment might be down-regulating the overall brain immune response to stroke at this sub-acute time point, so we also measured mRNA levels of another key pro-inflammatory mediator (iNOS) and an anti-inflammatory molecule (Ym1). Both iNOS and $\mathrm{Ym} 1$ were upregulated in response to stroke, and there was 1.5-fold less iNOS mRNA expression in peri-infarct cortex of clenbuterol-treated mice relative to saline-treated mice (Fig. 9a). These results suggest that clenbuterol treatment rapidly suppresses TNF $\alpha$ expression after stroke and prolonged clenbuterol treatment after stroke onset subsequently results in a suppression of both pro- and anti-inflammatory responses.

We next measured overall gene expression of pro- and anti-inflammatory signaling molecules in the peri-infarct cortex of Adrb2 ${ }^{\mathrm{cKO}}$ mice and Adrb2 ${ }^{\mathrm{WT}}$ controls 3 days after stroke. We hypothesized that we would not observe changes in cytokine gene expression, since we did not observe differences in Iba1+ cell numbers and morphology or infarct size in these mice. Unexpectedly, we found a 1.89-fold increase in TNFo mRNA in the peri-infarct cortex of Adrb2 ${ }^{\text {cKO }}$ mice compared to Adrb2 ${ }^{\text {WT }}$ mice (Fig. 9c), and a 3.15 -fold increase in IL-10 mRNA compared to Adrb2 ${ }^{\text {WT }}$ controls (Fig. 9d). Unlike with clenbuterol treatment, Adrb2 knockout did not change gene expression of iNOS (Fig. 9c). Expression of the anti-inflammatory marker $\mathrm{Ym} 1$ was also 3.24-fold higher in the brains of Adrb2 ${ }^{\text {cKO }}$ mice after stroke relative to Adrb2 ${ }^{\mathrm{WT}}$ controls (Fig. 9d). $\mathrm{Ym} 1$ is predominantly expressed by microglia and macrophages in the brain, so it appears that Adrb2 knockout from these cell types upregulates genes associated with both pro- and anti-inflammatory responses. These findings show that globally increasing $\beta 2$-adrenergic receptor stimulation with clenbuterol 


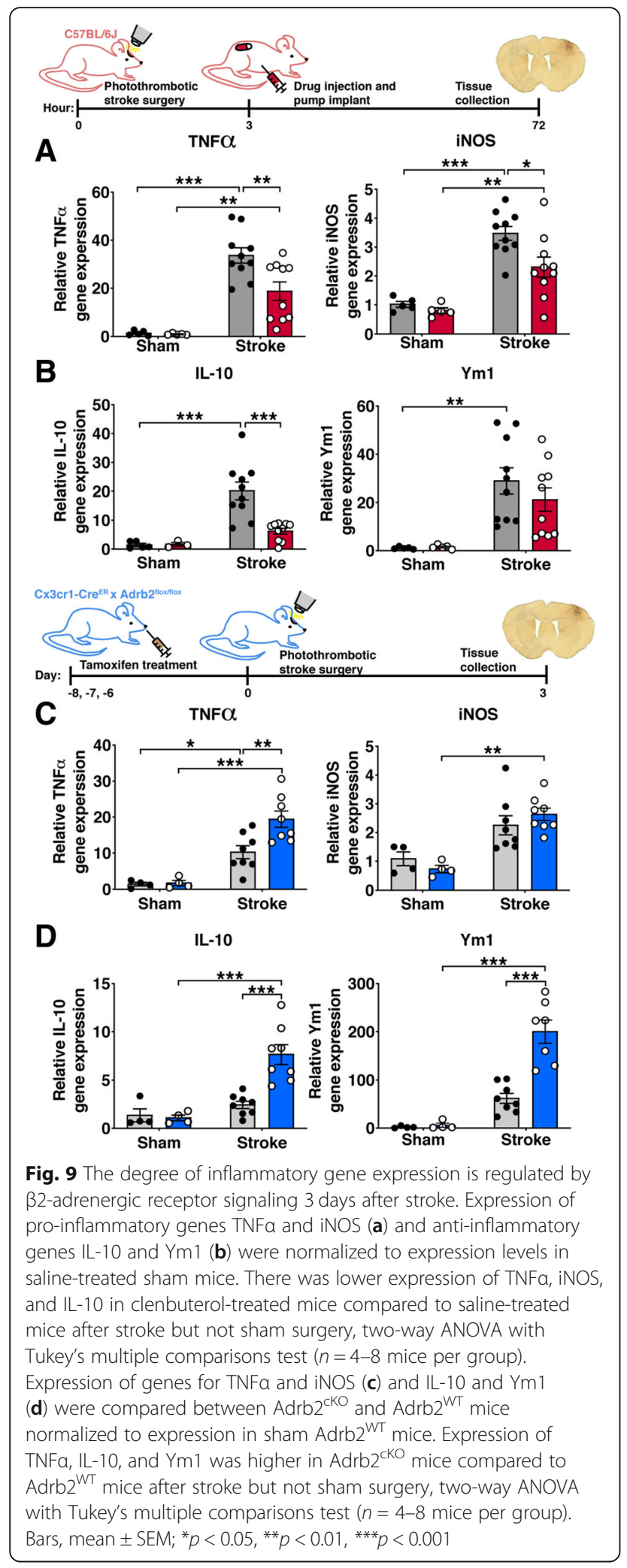

treatment dampens stroke-induced expression of both pro- and anti-inflammatory mediators in the post-stroke brain, whereas selective knockout of Adrb2 from
Cx3cr1-lineage cells is sufficient to increase post-stroke expression of both pro- and anti-inflammatory genes.

\section{Discussion}

We show here that increasing $\beta 2$-adrenergic stimulation after stroke onset causes enlarged morphology of microglia/MDMs surrounding the stroke, impairs proliferation of these cells, and reduces expression of pro-inflammatory TNF $\alpha$ early, followed by a later reduction in both pro- and anti-inflammatory cytokines. Augmented $\beta 2$-adrenergic signaling after stroke resulted in decreased blood pressure, increased heart rate, and increased infarct volume. Furthermore, we report that selective knockout of the $\beta 2$-adrenergic receptor causes opposite changes in the overall cytokine response in the post-stroke brain but does not affect microglial proliferation or morphology. Taken together, this indicates that $\beta 2$-adrenergic signaling is an important regulator of the microglia/MDM response to ischemic brain injury and that increasing it after stroke is detrimental.

There is a growing interest in understanding the impact of drugs targeting the sympathetic nervous system on stroke outcomes. Analyses of clinical stroke populations report that more than $50 \%$ of patients had prolonged use of $\beta$-blockers prior to experiencing stroke, some of which act on the $\beta 2$-receptor $[35,36]$. Also, after stroke, patients may receive therapy with pressors to increase their blood pressure, and some act on the $\beta 2$-receptor (e.g., norepinephrine and epinephrine), while others do not (e.g., neosynephrine) [6]. Clinically, the choice of adrenergic agent does not take into account direct or indirect effects on neuroinflammation, because these effects are unknown. Thus, it is critically important to understand how the sympathetic nervous system regulates the pathophysiology of stroke both in the periphery and in the central nervous system. $\beta$-blockers are also being investigated to prevent or treat post-stroke infection, which is believed to be caused in part by immunosuppression due to an increased outflow of the sympathetic nervous system. Some retrospective studies of $\beta$-blocker use in stroke patients found reduced infection and improved outcomes [37]. However, other similar studies failed to find improvements in infection rates and mortality with $\beta$-blocker use [36, 38, 39]. Further work will be required to understand whether post-stroke neuroinflammation in humans is analogous to neuroinflammation in mice. Our results imply that both non-selective $\beta$-blocker and pressor use in humans may be influencing stroke outcome.

The goal of our study was to directly assess the effect of $\beta 2$-adrenergic signaling on post-stroke neuroinflammation in the central nervous system by treating mice with the $\beta 2$-adrenergic receptor agonist clenbuterol after 
the ischemic event had already occurred. We used a stroke model that produces small-to-moderately-sized strokes that did not induce a significant increase in plasma norepinephrine and epinephrine. These results are in line with earlier findings from both human and animal studies that stroke size correlates with sympathetic response [3-5] and reflect that this model may not induce strokes that are large enough to increase plasma catecholamines. Our results demonstrate that pharmacologically supplementing $\beta 2$-adrenergic signaling after photothrombotic stroke suppresses the microglia/MDM response and the expression of inflammatory mediators. The pro-inflammatory cytokine TNF $\alpha$ was strongly reduced early after stroke with clenbuterol treatment and prolonged clenbuterol treatment after stroke led to a suppression of both pro- and anti-inflammatory mediators. These findings indicate an overall downregulation of the neuroimmune response with increased $\beta 2$-adrenergic signaling. The effects on cytokine expression are mediated by microglia and MDMs, as cell-specific knockout of the $\beta 2$-adrenergic receptor led to increased cytokine expression. As noted above, drugs regulating adrenergic signaling typically affect blood pressure by acting on adrenergic receptors expressed in the heart and in blood vessels [7]. We observed a reduction in rodent blood pressure and a compensatory increase in heart rate with the dose of clenbuterol used for this study. The neuroimmune effects of increased $\beta 2$-adrenergic stimulation after stroke may therefore be due to direct binding to $\beta 2$-adrenergic receptors expressed by immune cells as well as indirect effects mediated by changes in blood pressure. Further experimentation would be needed to determine if clenbuterol reduces cerebral perfusion specifically in the context of ischemic stroke.

The finding that the $\beta 2$-adrenergic receptor agonist clenbuterol leads to infarct expansion is in contrast to previous reports that rats or mice treated with clenbuterol 3-5 $\mathrm{h}$ prior to transient or permanent middle cerebral artery occlusion (MCAO) have reduced infarct volumes at 7 days post-stroke [10-12]. The disparities in outcomes between our observations and these previous studies may be explained by differences in stroke model, drug dose, or experimental timelines. For instance, particularly high doses of clenbuterol administered before stroke in rats increased ischemic damage, which the authors suggested was due to a dramatic reduction in blood pressure and therefore cerebral perfusion [12]. Lower doses of clenbuterol might confer neuroprotective effects without reducing blood pressure. However, pretreatment with clenbuterol at doses that reduced blood pressure was neuroprotective in another rodent stroke study [40], so it is unclear if the beneficial or detrimental effects of clenbuterol can be attributed to blood pressure changes alone. Another possibility is that clenbuterol targets different mechanisms in stroke pathophysiology depending on the timing of administration. Thus, clenbuterol treatment before stroke onset could mitigate the severity of the initial ischemic event, whereas clenbuterol treatment after stroke could reduce cerebral blood flow and suppress the normal neuroimmune response, resulting in exacerbation of the injury.

Interestingly, blocking $\beta 2$-adrenergic signaling is also reported to be neuroprotective in stroke models. For example, infarct size $24 \mathrm{~h}$ after transient MCAO is reduced in global $\beta 2$-adrenergic receptor knockout mice or mice treated with the $\beta 2$-adrenergic receptor antagonist ICI 118,551 prior to stroke $[13,14]$. Pre-treatment with the non-specific $\beta$-adrenergic receptor antagonist propranolol also reduces stroke size 3 days after MCAO in rats [41]. These three studies taken with our results suggest that blocking $\beta 2$-adrenergic receptor activity before stroke onset is neuroprotective, whereas increasing $\beta 2$-adrenergic receptor signaling after stroke is detrimental.

Our data show for the first time that $\beta 2$-adrenergic signaling specifically regulates the microglial and MDM response to ischemic stroke. We observed that clenbuterol treatment after stroke onset induced enlarged morphology of microglia/MDMs in the peri-infarct cortex and caused a dramatic reduction in microglia/MDM numbers and proliferation. These findings are in agreement with previous reports of the effects of $\beta 2$-adrenergic stimulation on microglia in vitro. In an acute brain slice model, stimulation of microglia with norepinephrine causes retraction of microglial processes and a shift to an ameboid morphology, dependent on $\beta 2$-adrenergic receptors [42]. Furthermore, stimulation of cultured rat microglia with $\beta 2$-adrenergic receptor agonists but not agonists for other adrenergic receptor subtypes suppresses microglial proliferation, possibly by elevating intracellular levels of cAMP [43]. $\beta 2$-adrenergic stimulation also suppresses the proliferation of other immune cell subtypes in vivo, such as group 2 innate lymphoid cells [44]. We assessed microglia/MDM numbers, activation, and proliferation in mice with Adrb2 specifically knocked out of monocyte-lineage cells in order to determine the effects of $\beta 2$-adrenergic receptor knockout on how these cells respond to stroke. We surprisingly did not see an increase in proliferation of microglia/MDMs in Adrb2 ${ }^{\mathrm{cKO}}$ mice, suggesting that cell-intrinsic $\beta 2$-adrenergic signaling may not regulate the effects of clenbuterol specifically on proliferation, and/or that there are other signals influencing proliferation in the absence of $\beta 2$-signaling. One possibility is that the effect of clenbuterol treatment on blood pressure and/or heart rate indirectly suppresses microglia/ MDM proliferation or impairs MDM trafficking into the injured brain. 
In addition to proliferation, a key function of microglia and MDMs in post-stroke inflammation is upregulation of inflammatory signaling molecules, such as TNF $\alpha$ and iNOS. In clenbuterol-treated mice, post-stroke expression of these genes was reduced. Notably, we report higher expression of TNF $\alpha$ in Adrb2 ${ }^{\text {cKO }}$ animals after stroke, in which the $\beta 2$-adrenergic receptor is specifically knocked out of microglia/MDMs. These results suggest that the changes in inflammatory gene expression with clenbuterol are directly mediated by intrinsic microglia/MDM $\beta 2$-adrenergic signaling rather than by indirect effects such as blood pressure. Our findings are in agreement with substantial previous literature that $\beta 2$-adrenergic stimulation is generally anti-inflammatory. For example, clenbuterol treatment reduces gene expression of TNF $\alpha$ and NFkb signaling in the brain after systemic LPS treatment [45]. The opposite effect occurs in rodent models of Alzheimer's disease, where disproportionate death of noradrenergic neurons causes increased expression of TNF $\alpha$ and iNOS, which can be reduced with norepinephrine administration [26]. In the context of neurodegeneration, it appears that loss of adrenergic signaling and the resulting increase in neuroinflammation exacerbates neuronal loss and speeds disease progression [25, 26, 46]. However, in our stroke model, increasing adrenergic signaling and reducing neuroinflammation was associated with increased stroke size. This finding may support the concept that a robust early neuroinflammatory response is actually beneficial for stroke outcomes, possibly by promoting clearance of harmful debris and dead cells, recruiting immune cells from the periphery, and forming a border around the stroke. Other studies also support this idea; for instance, depleting microglia from the brain before ischemic stroke or preventing MDM influx into the brain results in larger infarcts and worse outcomes [15, 47, 48]. Alternatively, it may be that blood pressure reduction by clenbuterol was responsible for the increased stroke size independent of clenbuterol-induced changes in neuroinflammation.

At $4 \mathrm{~h}$ post-stroke with clenbuterol treatment, we observed a significant decrease in TNF $\alpha$ gene expression in the stroke condition accompanied by a trend towards an increase in IL-10 gene expression. At 3 days after stroke, both cytokines are decreased by clenbuterol treatment, and both are increased in the Adrb $2^{\mathrm{cKO}}$ mice. Although the change in IL-10 with clenbuterol at $4 \mathrm{~h}$ after stroke is not significant, this data is consistent with previous reports that stimulation of $\beta 2$-adrenergic receptors with clenbuterol or norepinephrine induces IL-10 expression and suppresses TNF $\alpha$ expression [18, 24, 49-51]. The fact that 3 days later both are suppressed by clenbuterol likely results from a feedback loop between these two cytokines. Upregulation of TNF $\alpha$ typically stimulates expression of IL-10, which then downregulates TNF $\alpha$ to keep inflammation in check $[34,52]$. Thus, while the early effect is to inhibit pro-inflammatory TNF $\alpha$ expression, and perhaps augment anti-inflammatory IL-10, later the result is that the entire cytokine response is suppressed. This feedback relationship is likely also responsible for the increases in both cytokines at 3 days after stroke in the Adrb $2^{\text {cKO }}$ mice. Similar effects have been reported previously where neutralization of TNF $\alpha$ downregulates IL-10 [53] and in some cases, IL-10 and TNF $\alpha$ are downregulated by the same treatment [54].

The $\beta 2$-adrenergic receptor signals through multiple complex pathways; for this reason, it is likely that its effect on inflammation depends on cell type and context of the inflammatory insult. The $\beta 2$-adrenergic receptor is a 7-transmembrane receptor that is typically coupled to $G_{s}$ proteins. Canonical stimulation of $\beta 2$-adrenergic receptors expressed by immune cells increases intracellular cyclic-AMP and activates the protein kinase A pathway, generally resulting in reduced expression of pro-inflammatory factors such as TNF $\alpha$ and reactive oxygen species [7, 55-57]. However, the $\beta 2$-adrenergic receptor is capable of signaling through multiple other pathways. When the $\beta 2$-adrenergic receptor is phosphorylated, its coupling can switch from $G_{s}$ to $G_{i}$ which can actually have pro-inflammatory outcomes [58-60]. Additionally, $\beta$-arrestins can bind to the phosphorylated $\beta 2$-adrenergic receptor, with effects including desensitization, internalization, or induction of signaling through the alternate ERK1/ 2 pathway [58, 61]. Here, we observed predominantly canonical immunosuppressive effects of $\beta 2$-adrenergic receptor stimulation after stroke, although future work is needed to elucidate how $\beta 2$-adrenergic signaling pathways in the brain are regulated over time.

Another factor to consider in future studies is that $\beta 2$-adrenergic signaling may have particular effects on different cell types involved in the post-stroke inflammatory response. Both brain-resident microglia and MDMs infiltrating from the bloodstream have crucial, non-redundant roles in the neuroimmune response after stroke. A limitation of the present study is that we did not distinguish between these two cell types. In our clenbuterol experiment in which gene expression of TNF $\alpha$ was downregulated in brain tissue $4 \mathrm{~h}$ post-stroke, we can assume that these changes in inflammation are attributable to brain-resident cells, because blood-borne macrophages do not infiltrate the brain parenchyma at this early time point [16]. However, at 3 days post-stroke, we did not identify the cellular source of changes in inflammatory gene expression or distinguish between microglia or MDMs in the brain, since CD68 and Iba1 are markers known to label both cell types. Future experiments using cell-specific genetic markers might be useful for isolating these individual cell types and distinguishing the differential effects of $\beta 2$-adrenergic activity. However, the two cell types likely respond analogously. 
Previous literature generally suggests that $\beta 2$-adrenergic signaling affects microglia and peripheral macrophages similarly and results in similar effects on cytokines in both cell types to those we observed here $[57,62]$.

\section{Conclusion}

This work shows that increasing $\beta 2$-adrenergic receptor stimulation after ischemic stroke generally suppresses the neuroimmune response and leads to larger stroke volume. The specific effects of the $\beta 2$-adrenergic receptor agonist clenbuterol include reduced blood pressure, enlarged morphology and reduced proliferation of microglia/ MDMs, and reduced expression of both pro- and anti-inflammatory molecules in the brain. Selective knockout of the $\beta 2$-adrenergic receptor from microglia and monocyte-lineage cells increased expression of similar proand anti-inflammatory mediators. Since $\beta 2$-adrenergic receptor stimulation was not solely anti-inflammatory, we hypothesize that multiple complex signaling pathways underlie the effects of $\beta 2$-adrenergic signaling on post-stroke inflammation. Given that outflow of the sympathetic nervous system may be increased after stroke and that many stroke patients are prescribed with $\beta$-blockers or sympathomimetic adrenergic agonists, this work highlights the importance of understanding the role of the $\beta 2$-adrenergic signaling pathway on stroke pathophysiology and outcomes, and specifically that stimulating $\beta 2$-adrenergic signaling in the subacute period after stroke may be harmful.

\section{Abbreviations \\ CAMP: Cyclic AMP; IL-10: Interleukin-10; IL-1ß: Interleukin-1ß; IL-6: Interleukin-6; iNOS: Inducible nitric oxide species; LPS: Lipopolysaccharide; MCAO: Middle cerebral artery occlusion; MDM: Monocyte-derived macrophage; TNFa: Tumor necrosis factor-a}

\section{Acknowledgements}

We thank Dr. Gerard Karsenty for providing Adrb2 $2^{\text {flox/flox }}$ mice, Evan Brahms for the assistance with tissue collection, Li Zhu for the assistance in performing the catecholamine ELISA, Amy Dobberfuhl and Xiaoyuan Han for access to rodent blood pressure recording equipment, and Kristy Zera and Victoria Hernandez for proofreading the manuscript.

\section{Funding}

This work was supported by grants from the NIH to MSB (RO1 NS067132 and R21 NS098716). KJL received funding from a National Science Foundation Graduate Research Fellowship.

\section{Availability of data and materials}

Data generated and analyzed as part of this study are included in the manuscript or are available upon request from the corresponding author.

\section{Authors' contributions}

KJL and TCP performed the stroke surgeries. KJL conducted the behavioral assessments. KJL, STM, and JBD performed the drug treatments, tissue collection, histological analysis, and gene expression analysis. KJL and MSB conceived of the study, designed the experiments, and wrote the manuscript. All authors read and approved the final manuscript.

\section{Ethics approval and consent to participate}

All animal experimental procedures and husbandry were conducted in accordance with protocols approved by the Stanford Institutional Animal Care and Use Committee and the NIH Guide for Care and Use of Animals.

\section{Consent for publication}

Not applicable.

\section{Competing interests}

The authors declare that they have no competing interests.

\section{Publisher's Note}

Springer Nature remains neutral with regard to jurisdictional claims in published maps and institutional affiliations.

Received: 16 January 2019 Accepted: 9 May 2019

Published online: 28 May 2019

\section{References}

1. ladecola C, Anrather J. The immunology of stroke: from mechanisms to translation. Nat Med. 2011;17:796-808. https://doi.org/10.1038/nm.2399.

2. Kim E, Cho S. Microglia and monocyte-derived macrophages in stroke. Neurotherapeutics. 2016;13:702-18. https://doi.org/10.1007/s13311-016-0463-1.

3. Meyer JS, Stoica E, Pascu I, Shimazu K, Hartmann A. Catecholamine concentrations in CSF and plasma of patients with cerebral infarction and haemorrhage. Brain. 1973;96:277-88.

4. Sander D, Winbeck K, Klingelhöfer J, Etgen T, Conrad B. Prognostic relevance of pathological sympathetic activation after acute thromboembolic stroke. Neurology. 2001;57:833-8.

5. Mracsko E, Liesz A, Karcher S, Zorn M, Bari F, Veltkamp R. Differential effects of sympathetic nervous system and hypothalamic-pituitary-adrenal axis on systemic immune cells after severe experimental stroke. Brain Behav Immun. 2014:41:200-9.

6. Jauch EC, Saver JL, Adams HP, Bruno A, Connors JJB, Demaerschalk $B M$, et al. Guidelines for the early management of patients with acute ischemic stroke: a guideline for healthcare professionals from the American Heart Association/American Stroke Association. Stroke. 2013; 44:870-947.

7. Marino F, Cosentino M. Adrenergic modulation of immune cells: an update. Amino Acids. 2013:45:55-71.

8. Prass K, Meisel C, Höflich C, Braun J, Halle E, Wolf T, et al. Stroke-induced immunodeficiency promotes spontaneous bacterial infections and is mediated by sympathetic activation reversal by poststroke $T$ helper cell type 1-like immunostimulation. J Exp Med. 2003;198:725-36. https://doi.org/10. 1084/jem.20021098

9. McCulloch L, Smith CJ, McColl BW. Adrenergic-mediated loss of splenic marginal zone B cells contributes to infection susceptibility after stroke. Nat Commun. 2017:8:15051. https://doi.org/10.1038/ncomms15051.

10. Semkova I, Schilling M, Henrich-Noack P, Rami A, Krieglstein J. Clenbuterol protects mouse cerebral cortex and rat hippocampus from ischemic damage and attenuates glutamate neurotoxicity in cultured hippocampal neurons by induction of NGF. Brain Res. 1996;717:44-54 http://www.ncbi. nlm.nih.gov/pubmed/8738252

11. Culmsee C, Semkova I, Krieglstein J. NGF mediates the neuroprotective effect of the beta2-adrenoceptor agonist clenbuterol in vitro and in vivo: evidence from an NGF-antisense study. Neurochem Int. 1999;35:47-57 http://www.ncbi.n/m.nih.gov/pubmed/10403429.

12. Culmsee C, Stumm RK, Schäfer MK, Weihe E, Krieglstein J. Clenbuterol induces growth factor mRNA, activates astrocytes, and protects rat brain tissue against ischemic damage. Eur J Pharmacol. 1999;379:33-45 http:// www.ncbi.nlm.nih.gov/pubmed/10499369.

13. Han RQ, Ouyang YB, Xu L, Agrawal R, Patterson AJ, Giffard RG. Postischemic brain injury is attenuated in mice lacking the $\beta 2$-adrenergic receptor. Anesth Analg. 2009;108:280-7.

14. White RE, Palm C, Xu L, Ling E, Ginsburg M, Daigle BJ, et al. Mice lacking the $\beta 2$ adrenergic receptor have a unique genetic profile before and after focal brain ischaemia. ASN Neuro. 2012;4:343-56.

15. Wattananit S, Tornero D, Graubardt N, Memanishvili T, Monni E, Tatarishvili J, et al. Monocyte-derived macrophages contribute to spontaneous long-term functional recovery after stroke in mice. J Neurosci. 2016:36:4182-95. https:// doi.org/10.1523/JNEUROSCI.4317-15.2016. 
16. Gelderblom M, Leypoldt F, Steinbach K, Behrens D, Choe CU, Siler DA, et al. Temporal and spatial dynamics of cerebral immune cell accumulation in stroke. Stroke. 2009;40:1849-57.

17. Radojcic T, Baird S, Darko D, Smith D, Bulloch K. Changes in $\beta$-adrenergic receptor distribution on immunocytes during differentiation: an analysis of T cells and macrophages. J Neurosci Res. 1991;30:328-35.

18. Mori K, Ozaki E, Zhang B, Yang L, Yokoyama A, Takeda I, et al. Effects of norepinephrine on rat cultured microglial cells that express alpha1, alpha2, beta1 and beta2 adrenergic receptors. Neuropharmacology. 2002;43:1026-34.

19. Prinz M, Häusler KG, Kettenmann H. Hanisch UK. $\beta$-adrenergic receptor stimulation selectively inhibits IL-12p40 release in microglia. Brain Res. 2001; 899:264-70.

20. Zhang Y, Chen K, Sloan SA, Bennett ML, Scholze AR, Keeffe SO, et al. An RNA-sequencing transcriptome and splicing database of glia, neurons, and vascular cells of the cerebral cortex. J Neurosci. 2014;34:11929-47.

21. Ishii Y, Yamaizumi A, Kawakami A, Islam A, Choudhury ME, Takahashi H, et al. Anti-inflammatory effects of noradrenaline on LPS-treated microglial cells: suppression of NFKB nuclear translocation and subsequent STAT1 phosphorylation. Neurochem Int. 2015;90:56-66. https://doi.org/10.1016/j. neuint.2015.07.010.

22. Dello Russo C, Boullerne Al, Gavrilyuk V, Feinstein DL. Inhibition of microglial inflammatory responses by norepinephrine: effects on nitric oxide and interleukin-1 $\beta$ production. J Neuroinflammation. 2004;1:9.

23. Sharma M, Flood PM. $\beta$-arrestin2 regulates the anti-inflammatory effects of salmeterol in lipopolysaccharide-stimulated BV2 cells. J Neuroimmunol. 2018;325(July):10-9. https://doi.org/10.1016/j.jneuroim.2018.10.001.

24. Färber $\mathrm{K}$, Pannasch $\mathrm{U}$, Kettenmann $\mathrm{H}$. Dopamine and noradrenaline control distinct functions in rodent microglial cells. Mol Cell Neurosci. 2005:29:128-38.

25. Jiang L, Chen SH, Chu CH, Wang SJ, Oyarzabal E, Wilson B, et al. A novel role of microglial NADPH oxidase in mediating extra-synaptic function of norepinephrine in regulating brain immune homeostasis. Glia. 2015;63: 1057-72. https://doi.org/10.1002/glia.22801.

26. Heneka MT, Nadrigny F, Regen T, Martinez-Hernandez A, DumitrescuOzimek L, Terwel D, et al. Locus ceruleus controls Alzheimer's disease pathology by modulating microglial functions through norepinephrine. Proc Natl Acad Sci U S A. 2010;107:6058-63. https://doi.org/10.1073/ pnas.0909586107.

27. Parkhurst CN, Yang G, Ninan I, Savas JN, Yates JR, Lafaille JJ, et al. Microglia promote learning-dependent synapse formation through BDNF. Cell. 2013; 155:1596-609. https://doi.org/10.1016/j.cell.2013.11.030.

28. Labat-gest $\mathrm{V}$, Tomasi $\mathrm{S}$. Photothrombotic ischemia: a minimally invasive and reproducible photochemical cortical lesion model for mouse stroke studies. J Vis Exp. 2013:1-6. https://doi.org/10.3791/50370.

29. Livak KJ, Schmittgen TD. Analysis of relative gene expression data using realtime quantitative PCR and the 22DDCT method. Methods. 2001;25:402-8.

30. Schaar KL, Brenneman MM, Savitz SI. Functional assessments in the rodent stroke model. Exp Transl Stroke Med. 2010;2:1-11.

31. Cheng MY, Aswendt M, Steinberg GK. Optogenetic approaches to target specific neural circuits in post-stroke recovery. Neurotherapeutics. 2016;13: 325-40. https://doi.org/10.1007/s13311-015-0411-5.

32. Brown $\mathrm{R}$, Motulsky $\mathrm{H}$. Detecting outliers when fitting data with nonlinear regression - a new method based on robust nonlinear regression and the false discovery rate. BMC Bioinformatics. 2006;7:1-20. https://doi.org/10. 1186/1471-2105-7-123

33. Urra X, Villamor N, Planas AM. Harms and benefits of lymphocyte subpopulations in patients with acute stroke. NSC. 2009;158:1174-83. https://doi.org/10.1016/j.neuroscience.2008.06.014.

34. Armstrong L, Jordan N, Millar A. Interleukin 10 (IL-10) regulation of tumour necrosis factor a ( TNF-a) from human alveolar macrophages and peripheral blood monocytes. Thorax. 1996;51:143-9.

35. Eizenberg Y, Grossman E, Tanne D, Koton S. Pre admission treatment with betablockers in hypertensive patients with acute stroke and 3-month outcome-data from a national stroke registry. J Clin Hypertens. 2018;20:568-72.

36. Maier I, Becker J, Leyhe J, Schnieder M, Behme D, Psychogios M-K, et al. Influence of beta-blocker therapy on the risk of infections and death in patients at high risk for stroke induced immunodepression. PLoS One. 2018; 13. https://doi.org/10.1371/journal.pone.0196174.

37. Sykora M, Siarnik P, Diedler J, Lees KR, Alexandrov A, Bath PM, et al. BBlockers, pneumonia, and outcome after ischemic stroke: evidence from virtual international stroke trials archive. Stroke. 2015;46:1269-74. https://doi. org/10.1161/STROKEAHA.114.008260.

38. Westendorp WF, Nederkoorn PJ, Vermeij J-D, Dijkgraaf MG, van de Beek D. Post-stroke infection: a systematic review and meta-analysis. BMC Neurol. 2011;11:110. https://doi.org/10.1186/1471-2377-11-110.

39. Shim R, Wong CHY. Complex interplay of multiple biological systems that contribute to post-stroke infections. Brain Behav Immun. 2018;70:10-20. https://doi.org/10.1016/j.bbi.2018.03.019.

40. Zhu Y, Culmsee C, Semkova I, Krieglstein J. Stimulation of beta2adrenoceptors inhibits apoptosis in rat brain after transient forebrain ischemia. J Cereb Blood Flow Metab. 1998;18:1032-9. https://doi.org/10. 1097/00004647-199809000-00013.

41. Wang $H$, Deng QW, Peng AN, Xing FL, Zuo L, Li S, et al. $\beta$-arrestin2 functions as a key regulator in the sympathetic-triggered immunodepression after stroke. J Neuroinflammation. 2018:15:1-11.

42. Gyoneva S, Traynelis SF. Norepinephrine modulates the motility of resting and activated microglia via different adrenergic receptors. J Biol Chem. 2013;288:15291-302

43. Fujita H, Tanaka J, Maeda N, Sakanaka M. Adrenergic agonists suppress the proliferation of microglia through $\beta 2$ - adrenergic receptor. Neurosci Lett. 1998:242:37-40

44. Moriyama S, Brestoff JR, Flamar A-L, Moeller JB, Klose CSN, Rankin LC, et al. $\beta 2$-adrenergic receptor-mediated negative regulation of group 2 innate lymphoid cell responses. Science. 2018;359:1056-61.

45. Ryan KJ, Griffin É, Yssel JD, Ryan KM, McNamee EN, Harkin A, et al. Stimulation of central $\beta 2$-adrenoceptors suppresses NFkB activity in rat brain: a role for IKB. Neurochem Int. 2013;63:368-78. https://doi.org/10.1016/ j.neuint.2013.07.006.

46. Gleeson LC, Ryan KJ, Griffin EW, Connor TJ, Harkin A. The $\beta 2$-adrenoceptor agonist clenbuterol elicits neuroprotective, anti-inflammatory and neurotrophic actions in the kainic acid model of excitotoxicity. Brain Behav Immun. 2010;24:1354-61. https://doi.org/10.1016/j.bbi.2010.06.015.

47. Szalay G, Martinecz B, Lénárt N, Környei Z, Orsolits B, Judák L, et al. Microglia protect against brain injury and their selective elimination dysregulates neuronal network activity after stroke. Nat Commun. 2016;7. https://doi.org/ 10.1038/ncomms 11499.

48. Shichita T, Ito M, Morita R, Komai K, Noguchi Y, Ooboshi H, et al. MAFB prevents excess inflammation after ischemic stroke by accelerating clearance of damage signals through MSR1. Nat Med. 2017;23:723-32. https://doi.org/10.1038/nm.4312.

49. McNamee EN, Ryan KM, Griffin EW, González-Reyes RE, Ryan KJ, Harkin A, et al. Noradrenaline acting at central beta-adrenoceptors induces interleukin10 and suppressor of cytokine signaling-3 expression in rat brain: implications for neurodegeneration. Brain Behav Immun. 2010;24:660-71. https://doi.org/10.1016/j.bbi.2010.02.005.

50. Giordani L, Cuzziol N, Del Pinto T, Sanchez M, Maccari S, Massimi A, et al. $\beta 2$-agonist clenbuterol hinders human monocyte differentiation into dendritic cells. Exp Cell Res. 2015;339:163-73. https://doi.org/10.1016/j. yexcr.2015.10.032.

51. Ağaç D, Estrada LD, Maples R, Hooper LV, Farrar JD. The $\beta 2$-adrenergic receptor controls inflammation by driving rapid IL-10 secretion. Brain Behav Immun. 2018;74:176-85.

52. Platzer C, Meisel C, Vogt K, Platzer M, Volk HD. Up-regulation of monocytic IL-10 by tumor necrosis factor-a and CAMP elevating drugs. Int Immunol. 1995; 7:517-23.

53. Sato TA, Keelan JA, Mitchell MD. Critical paracrine interactions between TNF-alpha and IL-10 regulate lipopolysaccharide-stimulated human choriodecidual cytokine and prostaglandin E2 production. J Immunol. 2003; 170:158-66. https://doi.org/10.4049/jimmunol.170.1.158.

54. Meng A, Wang B, Zhang X, Qi N, Liu D, Wu J. Additive suppression of LPS-induced IL-10 and TNF-a by pre-treatment of dexamethasone and SB203580 in a murine alveolar macrophage cell line (MH-S). Inflammation. 2015;38:1260-6.

55. Farmer P, Pugin J. $\beta$-Adrenergic agonists exert their "anti-inflammatory" effects in monocytic cells through the IKB/NF-KB pathway. Am J Physiol Lung Cell Mol Physiol. 2000;279:675-82.

56. Nance DM, Sanders VM. Autonomic innervation and regulation of the immune system (1987-2007). Brain Behav Immun. 2007;21:736-45. https:/ doi.org/10.1016/j.bbi.2007.03.008.

57. Izeboud CA, Monshouwer M, Van MASJPAM, Witkamp RF. The $\beta$ adrenoceptor agonist clenbuterol is a potent inhibitor of the LPS- 
induced production of TNF- $a$ and IL- 6 in vitro and in vivo. Inflamm Res 1999:48:497-502.

58. Lorton $\mathrm{D}$, Bellinger DL. Molecular mechanisms underlying $\beta$-adrenergic receptor-mediated cross-talk between sympathetic neurons and immune cells. Int J Mol Sci. 2015;16:5635-65.

59. Kolmus K, Tavernier J, Gerlo S. $\beta 2$-adrenergic receptors in immunity and inflammation: stressing NF-kB. Brain Behav Immun. 2015;45:297-310. https:// doi.org/10.1016/j.bbi.2014.10.007.

60. Szelenyi J, Selmeczy Z, Brozik A, Medgyesi D, Magocsi M. Dual $\beta$-adrenergic modulation in the immune system: stimulus-dependent effect of isoproterenol on MAPK activation and inflammatory mediator production in macrophages. Neurochem Int. 2006;49:94-103.

61. Lefkowitz RJ. G protein-coupled receptors. J Biol Chem. 1998;273:18677-80.

62. Stanojević S, Dimitrijević M, Kuštrimović N, Mitić K, Vujić V, Leposavić G. Adrenal hormone deprivation affects macrophage catecholamine metabolism and $\beta 2$-adrenoceptor density, but not propranolol stimulation of tumour necrosis factor-a production. Exp Physiol. 2013;98:665-78.

Ready to submit your research? Choose BMC and benefit from:

- fast, convenient online submission

- thorough peer review by experienced researchers in your field

- rapid publication on acceptance

- support for research data, including large and complex data types

- gold Open Access which fosters wider collaboration and increased citations

- maximum visibility for your research: over $100 \mathrm{M}$ website views per year

At $\mathrm{BMC}$, research is always in progress.

Learn more biomedcentral.com/submissions 